\title{
Riclinoctaose Attenuates Renal Ischemia-Reperfusion Injury by the Regulation of Macrophage Polarization
}

\author{
Yang Zhao ${ }^{\dagger}$, Zhao Ding ${ }^{\dagger}$, Wenhao Ge, Junhao Liu, Xi Xu, Rui Cheng* and Jianfa Zhang * \\ Center for Molecular Metabolism, Nanjing University of Science and Technology, Nanjing, China
}

\section{OPEN ACCESS}

Edited by:

Salvatore Salomone,

University of Catania, Italy

Reviewed by:

Sjoerd Schetters,

Flanders Institute for Biotechnology,

Belgium

$\mathrm{NaXie}$,

Independent researcher, Chengdu,

China

*Correspondence:

Jianfa Zhang

jzzhang@njust.edu.cn

Rui Cheng

chengrui@njust.edu.cn

${ }^{t}$ These authors have contributed equally to this work and share first authorship

Specialty section:

This article was submitted to Experimental Pharmacology and Drug Discovery,

a section of the journal

Frontiers in Pharmacology

Received: 22 July 2021 Accepted: 24 September 2021

Published: 13 October 2021

Citation:

Zhao Y, Ding Z, Ge W, Liu J, Xu X,

Cheng $R$ and Zhang J (2021)

Riclinoctaose Attenuates Renal Ischemia-Reperfusion Injury by the

Regulation of

Macrophage Polarization.

Front. Pharmacol. 12:745425.

doi: 10.3389/fphar.2021.745425
Renal ischemia-reperfusion injury is a major trigger of acute kidney injury and leads to permanent renal impairment, and effective therapies remain unresolved. Riclinoctaose is an immunomodulatory octasaccharide composed of glucose and galactose monomers. Here we investigated whether riclinoctaose protects against renal ischemia-reperfusion injury. In mice, pretreatment with riclinoctaose significantly improved renal function, structure, and the inflammatory response after renal ischemia-reperfusion. Flow cytometry analysis revealed that riclinoctaose inhibited ischemia-reperfusion-induced M1 macrophage polarization and facilitated M2 macrophage recruitment into the kidneys. In isolated mouse bone marrow-derived macrophages, pretreatment with riclinoctaose promoted the macrophage polarization toward M2-like phenotype. The inhibitor of Nrf-2/HO-1 brusatol diminished the effects of riclinoctaose on macrophage polarization. In mice, intravenous injection with riclinoctaose-pretreated bone marrowderived macrophages also protected against renal ischemia-reperfusion injury. Fluorescence-labeled riclinoctaose specifically bound to the membrane of macrophages. Interfering with $\mathrm{mDC}$-SIGN blocked the riclinoctaose function on M2 polarization of macrophages, consequently impairing the renoprotective effect of riclinoctaose. Our results revealed that riclinoctaose is a potential therapeutic agent in preventing renal ischemia-reperfusion injury.

Keywords: riclinoctaose, ischemia-reperfusion, immunomodulatory, macrophage polarization, DC-SIGN

\section{INTRODUCTION}

Renal ischemia-reperfusion injury (IRI) is a highly heterogeneous and common clinical syndrome, encompassing a spectrum of risk factors and affecting 13.3 million patients every year (Devarajan, 2006). IRI is a two-stage pathophysiological process characterized by restriction of blood supply to the kidney and restoration of blood and oxygen. The pathogenesis of renal IRI is complex and involves several mechanisms, including activation of neutrophils, oxidative stress, ATP and glycogen depletion, as well as cellular metabolic stress caused by mitochondrial dysfunction (Sharfuddin and Molitoris, 2011; Zuk and Bonventre, 2016; Gonsalez et al., 2019). In addition, several apoptotic pathways, including the intrinsic Bcl-2 family and regulatory p53 pathways, seem to be activated during renal IRI (Sharfuddin and Molitoris, 2011). These factors inevitably cause initial cell death and promote renal tubulointerstitial fibrosis in the chronic phase (Boor and Floege, 2015). 
IRI is likely mediated by the immune cells in the kidney, and the predominant cell type is macrophage (Huen and Cantley, 2017; Yan et al., 2020). Macrophages play an essential role in driving the progression or repair of IRI, depending on their activation stage and phenotype (Huen and Cantley, 2017). Thus, ischemia/reperfusion (I/R)-related macrophage activations and inflammatory cytokine productions are critical to the graft dysfunction and even the occurrence of primary nonfunction. Increasing evidence supports the importance of M1/M2 polarization of macrophage in tissue injury and repair during IRI (Ricardo et al., 2008; Vinuesa et al., 2008). Current evidence indicates that heme oxygenases-1 (HO-1) induction can switch the phenotypic to an anti-inflammatory phenotype, M2 macrophages, and enhance phagocytic capacity, suggesting that HO-1 induction in macrophages is a potential therapeutic approach for IRI (Ferenbach et al., 2010; Bolisetty et al., 2017; Zhang et al., 2018).

There are several therapies in combat with IRI, including ischemic preconditioning, gene therapy, and pharmacotherapy (Gonsalez et al., 2019). Ischemic preconditioning consists of cycles of mild ischemic stress, which elicit tolerance against subsequent severe ischemia and is an essential tool for clinical management of IRI (Livingston et al., 2019). Gene therapy, such as RNA interference targeting transcription factors that drive inflammation and fibrosis, has also been reported to be therapeutically effective in experimental renal IRI (Haddad et al., 2021; Tang et al., 2021; Zhuang et al., 2021). The therapeutic efficacy of the RNA interference is dependent on its stability, which increases the difficulty and cost of clinical utility. Medication treatments for renal IRI mainly include the following. Designed pharmaceuticals such as doxycycline, levosimendan, and iloprost have been reported to reduce renal oxidative injury and facilitate repair (Kucuk et al., 2009; Ihtiyar et al., 2011). Leptin, ascorbic acid, and B12 act as natural antioxidants to protect against $\mathrm{I} / \mathrm{R}$-induced renal damage (Erkasap et al., 2004; Korkmaz and Kolankaya, 2009; Li et al., 2020). However, the available drugs have multiple limitations, and the development of effective and comprehensive therapeutic strategies is essential for treating IRI.

Succinoglycan is an exopolysaccharide produced mainly by a large number of soil microbes of Agrobacterium, Rhizobium, or Pseudomonas genera, etc. Succinoglycan oligosaccharide (riclinoctaose) is the depolymerized form of a specific succinoglycan, riclin, which has shown superior antiinflammatory, anti-tumor activity, and immunogenicity (Yang et al., 2019; Yang et al., 2021). Riclinoctaose is a linear oligooctasaccharide, composed of one galactose and seven glucose residues, with a pyruvate group linked to the terminal glucose residue (Wang et al., 2021). Compared with other known functional oligosaccharides, riclinoctaose is an oligooctasaccharide rather than a mixture of oligomers with different degrees of polymerization. The amphipathic properties against water and low toxicity allow succinoglycan oligosaccharides to be used in improving the solubility and bioavailability of poorly soluble therapeutic agents (Choi et al., 2012). Our previous investigation has also shown that riclinoctaose modulates the composition and metabolism of gut microbiota and thus improves host health (Wang et al., 2021).

In the present study, we investigated the therapeutic effects of riclinoctaose on preventing renal IRI in mice. We demonstrated that riclinoctaose had a significant protective effect on renal IRI, which depended on the moue DC-SIGN (mDC-SIGN) of macrophages. Our results revealed that riclinoctaose is a potential therapeutic agent in preventing renal IRI.

\section{MATERIAL AND METHODS}

\section{Chemicals and Materials}

Riclinoctaose was an oligooctasaccharide depolymerized from a succinoglycan, riclin, and prepared and purified as described in our previous study (Wang et al., 2021). The structure was characterized by electrospray ionization mass spectrometry (ESI-MS), Fourier-transform infrared (FT-IR), mass spectrum (MS), ${ }^{1} \mathrm{H}$ nuclear magnetic resonance (NMR), and ${ }^{13} \mathrm{C} \mathrm{NMR}$ spectroscopic methods. The molecular weight is 1,384 . The purity of the compound was greater than $99.4 \%$. The remaining components was traces of inorganic salts. Riclinoctaose was re-dissolved in $0.9 \%$ saline and filter sterilized $(0.22 \mu \mathrm{m}$ filters).

\section{Animals}

Wild-type male C57BL/6J mice (6-8 weeks old, 18-22 g) were purchased from Model Animal Research Center of Nanjing University and housed in standard cages on a $12 \mathrm{~h}$ light/dark cycle and were allowed free access to food and water. All animal care and use procedures were in accordance with the guidelines of the Institutional Animal Care and Use Committee at Nanjing University of Science and Technology (ACUC-NUST-20190218).

\section{Cell Culture}

Mouse macrophage cell line RAW 264.7 cells and mouse fibroblast cell line NIH-3T3 cells were maintained in DMEM (Gibco, Germany) supplemented with $10 \%$ fetal bovine serum (FBS) (Gibco, Germany) and 1\% penicillin-streptomycin. Mouse hepatocyte cell line AML12 cells were cultured in DMEM/F12 medium (Gibco, Germany) supplemented with 10\% FBS (Gibco, Germany), 1\% Insulin-Transferrin-Selenium (Gibco, Germany), $40 \mathrm{ng} / \mathrm{ml}$ dexamethasone (Sigma Aldrich), and 1\% penicillinstreptomycin. BMDMs were cultured in DMEM (Gibco, Germany), supplemented with 10\% FBS, 20\% L929-MCSF supernatant, and $1 \%$ penicillin-streptomycin.

\section{Renal I/R Model}

Mice were anesthetized using isoflurane with oxygen $(2 \%, 0.5 \mathrm{~L} /$ h). The core body temperature was maintained around $37^{\circ} \mathrm{C}$ by an electrically heated plate. The abdomen was shaved, and a midline incision was made to expose the renal hilum. Then, the bilateral renal pedicle was occluded by non-traumatic vascular clamps for $30 \mathrm{~min}$. Following reperfusion, the peritoneum was closed with a $4 / 0$ suture, and $0.5 \mathrm{~mL}$ sterile saline was administered intraperitoneally. The mice were placed into a ventilated incubator at $28^{\circ} \mathrm{C}$ for $2 \mathrm{~h}$ and then returned back to their home cages. 24 and $48 \mathrm{~h}$ after the bilateral renal reperfusion, 
TABLE 1 | Primer sequences for the quantitative real-time polymerase chain reactions.

\begin{tabular}{|c|c|c|}
\hline Gene & Type & Sequence $\left(5^{\prime}-3^{\prime}\right)$ \\
\hline \multirow[t]{2}{*}{$\beta$-actin } & Forward & GAT CAT TGC TCC TCC TGA GC \\
\hline & Reverse & ACT CCT GCT TGC TGA TCC AC \\
\hline \multirow[t]{2}{*}{ Hprt } & Forward & TCA GTC AAC GGG GGA CAT AAA \\
\hline & Reverse & GGG GCT GTA CTG CTT AAC CAG \\
\hline \multirow[t]{2}{*}{ Kim1 } & Forward & CAA GTT AAA CCA GAG ATT CCC AC \\
\hline & Reverse & CGT GAT GCT GAG AAG TCT CA \\
\hline \multirow[t]{2}{*}{ Vimentin } & Forward & CTG GTT GAC ACC CAC TCA AA \\
\hline & Reverse & CGT GAT GCT GAG AAG TCT CA \\
\hline \multirow[t]{2}{*}{ Fibronectin } & Forward & CAA GTC GAT GCC ATC CCA G \\
\hline & Reverse & CTG GCT GTA AAC CTG TAA TGG \\
\hline \multirow[t]{2}{*}{$\operatorname{Tgf} \beta 1$} & Forward & TGC TTC AGC TCC ACA GAG AA \\
\hline & Reverse & GTG GAT CCA CTT CCA ACC CA \\
\hline \multirow[t]{2}{*}{$\operatorname{Tgf} \beta 2$} & Forward & ATT CCC AGC TTC TGG CTC AA \\
\hline & Reverse & GTC ATG GTC CCA GCA CTC G \\
\hline \multirow[t]{2}{*}{ Sod1 } & Forward & CCA TTG AAG ATC GTG TGA TCT C \\
\hline & Reverse & CTT GTT TCT CAT GGA CCA CC \\
\hline \multirow[t]{2}{*}{ Sod2 } & Forward & AAG GAA CAA GGT CGC TTA CA \\
\hline & Reverse & AGC AGC GGA ATA AGG CCT GT \\
\hline \multirow[t]{2}{*}{ Sod3 } & Forward & СCT TCT TGT TCT ACG GCT TG \\
\hline & Reverse & CTG GAC TCC CCT GGA TIT GA \\
\hline \multirow[t]{2}{*}{ Gpx1 } & Forward & GTC TGG GAC CTC GTG GAC \\
\hline & Reverse & TTC TTG CCA TTC TCC TGG TG \\
\hline \multirow[t]{2}{*}{ Bcl2 } & Forward & AGG ATA ACG GAG GCT GGG AT \\
\hline & Reverse & CTा CAG AGA CAG CCA GGA GA \\
\hline \multirow[t]{2}{*}{ Bax } & Forward & CTG AGC TGA CCT TGG AGC \\
\hline & Reverse & GAC TCC AGC CAC AAA GAT G \\
\hline \multirow[t]{2}{*}{ P53 } & Forward & TGC TCC GAT GGT GAT GGC CT \\
\hline & Reverse & TGT GGC GAA AAG TCT GCC TG \\
\hline \multirow[t]{2}{*}{$M C P-1$} & Forward & GCT GGA GCA TCC ACG TGT T \\
\hline & Reverse & ATC TTG CTG GTG AAT GTG TAG CA \\
\hline \multirow[t]{2}{*}{$I L-1 \beta$} & Forward & GAG CTT CAG GCA GGC AGT ATC \\
\hline & Reverse & GTA TAG ATT CTT TCC गा GAG GC \\
\hline \multirow[t]{2}{*}{ Icam } & Forward & ACT GAG GAG TTC GAC AGA AC \\
\hline & Reverse & AGG ACC GGA GCT GAA AAG Tा \\
\hline \multirow[t]{2}{*}{ TIr4 } & Forward & GGT GAG AAA TGA GCT GGT AAA G \\
\hline & Reverse & GCA ATG GCT ACA CCA GGA AT \\
\hline \multirow[t]{2}{*}{$\mathrm{HO}-1$} & Forward & GGG TGA TAG AAG AGG CCA AGA \\
\hline & Reverse & AGC TCC TGC AAC TCC TCA AA \\
\hline \multirow[t]{2}{*}{$\operatorname{Arg}-1$} & Forward & CAT GGG CAA CCT GTG TCC TT \\
\hline & Reverse & CGA TGT CTT TGG CAG ATA TGC A \\
\hline \multirow[t]{2}{*}{ NQO-1 } & Forward & AGC CAA TCA GCG TTC GGT AT \\
\hline & Reverse & GTA GTT GAA TGA TGT CTT CT \\
\hline \multirow[t]{2}{*}{$11-10$} & Forward & СTC TCT GCA AGA GAC TTC CA \\
\hline & Reverse & CTC TCC GGA CTT GTG AAG TA \\
\hline
\end{tabular}

mice were euthanized. Plasma and tissue samples were harvested for analysis of renal function.

\section{Histology and Immunohistochemistry}

For histological analysis, tissues were fixed with $4 \%$ paraformaldehyde for $24-48 \mathrm{~h}$, paraffin sectioned $(5 \mu \mathrm{m})$, and stained with hematoxylin and eosin, with Periodic acid Schiff, or with Masson's Trichrome. For immunohistochemistry, paraffin tissue sections were dewaxed and blocked with $3 \%$ goat serum, $1 \%$ BSA, $0.1 \%$ Triton X-100 in PBS for $1 \mathrm{~h}$ at room temperature. Sections were incubated with antibodies specific to BCL-2 (\#ab692, Abcam), Bax (\#14796, Cell Signaling), and F4/80 (\#30325, Cell Signaling) at $4^{\circ} \mathrm{C}$ overnight, treated with TSAbiotin (1:50) and visualized with $2,2^{\prime}$-diaminobenzidine tetrahydrochloride. TUNEL staining was performed using the DeadEnd Fluorometric TUNEL System (Promega). Staining quantification was performed using ImageJ software.

\section{Biochemical Analyses}

Serum creatinine and blood urea nitrogen were measured by commercial kits (C013-1-1 and C011-2-1, Nanjing Jiancheng, China). Relative LDH release was determined using a commercial kit LDH (BC0680, Solarbio, Beijing, China). The levels of renal malondialdehyde (MDA), superoxide dismutase (SOD), catalase (CAT), and glutathione peroxidase (GSH-Px) were measured using specific kits (A003-1, A001-1, A007-1, A061-1, Nanjing Jiancheng, China). Data were normalized to total protein concentration determined by the BCA protein assay kit (P0012S, Beyotime, China).

\section{Quantitative Real-Time PCR}

Total RNA was extracted from snap-frozen renal tissue sections and isolated from BMDMs using Karrol reagent (Karroten, Nanjing, China), and subsequently converted to cDNA using reverse transcript kits (Karroten, Nanjing, China). mRNA level was analyzed by reverse transcriptase-PCR with SYBR green PCR master mix (Karroten, Nanjing, China). The expression of the target gene was normalized to mouse housekeeping gene $\beta$-actin and Hprt. Values are expressed as relative fold induction. Primer sequences are displayed in Table $\mathbf{1 .}$

\section{Western Blot Analysis}

Snap frozen kidneys were lysed in a radioimmunoprecipitation assay (RIPA) buffer. After total protein normalized (BCA protein assay kit, P0012S, Beyotime, China), Total protein of 20-40 $\mu \mathrm{g} /$ lane was separated by $8-10 \%$ SDS-PAGE gel electrophoresis and transferred onto $0.22 \mu \mathrm{m} \mathrm{NC}$ membranes. After blocking with $5 \%$ skimmed milk or $3 \%$ BSA diluted in Tris buffer saline plus $0.1 \%$ Tween 20 (TBST) for $1 \mathrm{~h}$ at room temperature, membranes were incubated overnight with $\beta$-actin (\#20536-1AP, Proteintech), BCL-2 (\#ab692, Abcam), and BAX (\#14796, Cell Signaling). Then membranes were incubated $1 \mathrm{~h}$ with secondary antibody (Jackson Immuno Research, 1:10,000). Enhanced chemiluminescence (ECL) was performed using ECL kit (WB12, Solarbio, Beijing, China), visualized and analyzed by Clinx ChemiCapture software (Clinx, Shanghai, China). Individual protein level was quantified by normalizing its intensity to the $\beta$-actin in the same sample and expressed relative to the levels of the respective control group, the mean of which was set as one.

\section{${ }^{1} \mathrm{H}$ NMR Sample Preparation and NMR Spectroscopy}

Polar metabolites were extracted from the kidneys as described (Beckonert et al., 2007). Briefly, approximately $200 \mathrm{mg}$ frozen kidney samples were homogenized in ice-cold solvent buffer (50\% acetonitrile $/ 50 \%$ water, $1 \mathrm{ml} / 200 \mathrm{mg}$ tissue). After centrifugation at $12,000 \mathrm{~g}$ for $10 \mathrm{~min}$ at $4^{\circ} \mathrm{C}$, the supernatant was collected and lyophilized. The polar tissue extracts were resuspended in $580 \mathrm{ml}$ NMR buffer $(100 \mathrm{mM}$ sodium phosphate buffer, $\mathrm{pH} 7.4$, in $\mathrm{D} 2 \mathrm{O}$, containing $0.5 \mathrm{mM}$ TSP) 
and then centrifuged at $12,000 \mathrm{~g}$ for $5 \mathrm{~min}$. NMR spectra were recorded on a Bruker AVANCE III $500 \mathrm{MHz}$ NMR spectrometer (Bruker GmbH, Karlsruhe, Germany) at $298 \mathrm{~K}$.

\section{Spectra Processing and Data Analysis}

All NMR spectra were manually adjusted for phase and baseline correction and peak alignment using Bruker Topspin 3.0 software (Bruker GmbH, Karlsruhe, Germany) by the same person. MestReNova (Version 8.0.1, Mestrelab Research SL) was used to convert ${ }^{1} \mathrm{H}$ NMR spectra to ASCII files. The water signal and affected regions from 4.5 to $5.5 \mathrm{ppm}$ were eliminated. The data were normalized to the total area of the remaining spectra. $\mathrm{R}$ software (http://cran.r-project.org/) was performed for multivariate statistical analysis. The NMR data were first analyzed using principal component analysis (PCA), partialleast-squares-discriminant analysis (PLS-DA), and principal coordinate analysis (PCoA) to obtain a general overview of the metabolic patterns. Orthogonal signal correction-partial least square discriminate analysis (OPLS-DA) was then performed to reveal differential metabolic changes in kidneys between two groups. Metabolites were identified by comparing NMR spectra with original database curated from published paper (Jarak et al., 2017; Mora-Ortiz et al., 2019a; Mora-Ortiz et al., 2019b) and software Chenomx NMR suite 7.7 (Chenomx Inc., Edmonton, $\mathrm{AB}$, Canada). The fold-change values of metabolites and their associated $p$-values were calculated and visualized in colored tables.

\section{Isolation and Culture of BMDMs}

BMDMs were isolated from C57BL/6J mice as described (Roach et al., 2001). In brief, mice were euthanized by cervical dislocation, and bone marrow was isolated from femurs and tibias using an aseptic technique. Erythrocytes were lysed in red blood lysing buffer on ice for $5 \mathrm{~min}$. Progenitor cell suspensions were cultured for 7 days in macrophage complete medium (DMEM with $10 \%$ FBS, $100 \mathrm{U} / \mathrm{mL}$ penicillin, $100 \mu \mathrm{g} / \mathrm{mL}$ streptomycin, and 20\% MCSF-containing L929 fibroblast culture supernatant). The adherent cells after 7 days in culture were macrophages.

\section{Macrophage Phagocytosis Assays}

Strain-matched thymi were filtered through a 200-mesh screen to collect single cells, and the liberated thymocytes were stained with Cell Tracker Green CMFDA (40721ES60, Yeasen, Shanghai, China). Then, thymocyte apoptosis was induced by overnight culture in RPMI 1640 with the final $1 \mu \mathrm{mol} / \mathrm{L}$ of dexamethasone in (50-02-2, Sigma-Aldrich). BMDMs were seeded in a 24-well plate and incubated with Lyso-Tracker Red (L8010, Solarbio, Beijing, China) for $15 \mathrm{~min}$. Macrophages were then overlaid with apoptotic thymocytes at a ratio of 10:1 for $1 \mathrm{~h}$. After three times of washing with ice-cold PBS, colocalization between the red phagolysosome and green apoptotic thymocytes to represent phagocytosis using fluorescence microscopy.

\section{Intravenous Administration of BMDMs}

The intravenous injections of BMDMs were implemented as described (Ferenbach et al., 2010). The BMDMs cells were digested using pancreatic enzymes without EDTA and collected by centrifugation at $2000 \mathrm{rpm}$ and then washed three times with PBS. The cells were then counted and kept on ice until IV injection into animals via the tail vein $1 \mathrm{~h}$ before bilateral clamping of renal arteries. For the Nrf-2/HO-1 pathway blocking experiment, BMDMs were pretreated with brusatol $(160 \mathrm{nM})$ for $1 \mathrm{~h}$ before treatment with riclinoctaose.

\section{Flow Cytometric Analysis}

Whole kidney samples were collected $24 \mathrm{~h}$ after reperfusion and minced into small pieces $\left(1-2 \mathrm{~mm}^{3}\right)$ in ice-cold PBS and collected by centrifugation ( $500 \mathrm{~g}, 5 \mathrm{~min}$ ). Collected tissue was incubated in collagenase $4(1 \mathrm{mg} / \mathrm{ml}$, Sigma-Aldrich) and DNAse $1(0.1 \mathrm{mg} /$ $\mathrm{ml}$, Roche, Woerden, Netherlands) in RPMI 1640 medium for $1 \mathrm{~h}$ at $37^{\circ} \mathrm{C}$ with gentle agitation. After that, cells were triturated through a $70-\mu \mathrm{m}$ cell strainer, centrifuged, and enriched. The isolated cells were counted after erythrocyte lysis (ACK lysis buffer, A1049201, ThermoFisher) and washed with RPMI-1640 cell culture medium for further analysis. Approximately 100,000 harvested cells from the kidney. Cells were incubated with FITC rat anti-mouse CD11b Clone M1/70 (eBioscience Cat\#: 17-0112-82), PerCP rat anti-mouse Ly-6G Clone $1 \mathrm{~A} 8$ (Biolegend Cat\#: 127,653), APC rat anti-mouse F4/80 Clone BM8 (Biolegend Cat\#: 123,115), PE rat anti-mouse CD206 (MMR) Clone C068C2 (Biolegend Cat\#: 141,705) were used. The analysis was performed by a NovoCyte flow cytometer (ACEA Bioscience Inc. San Francisco, CA, U.S.A) and analyzed using NovoExpress 1.2.3 software (ACEA Bioscience). The gating strategy is showed in Supplementary Figure S1.

\section{Colocalization Experiment}

Raw 267.4 cells were seeded to $35 \mathrm{~mm}$ glass-bottom microscope dishes $(801,002$, Nest $)$ at a proper density and cultured overnight. The cells were cultured with media containing $200 \mu \mathrm{M}$ riclinoctaose for $6 \mathrm{~h}$, then incubated with fresh media for $1 \mathrm{~h}$ at $37^{\circ} \mathrm{C}$, followed by incubating with the fluorescent lipophilic cell tracer of DiI (D8700, Solarbio) according to the manual methods. After three washes with PBS, confocal images were captured by a Nikon A1 confocal laser microscope (Nikon, Tokyo, Japan).

\section{Receptor Blockade}

For receptor-blocking experiments, mannan $(200 \mu \mathrm{g} / \mathrm{ml})$, laminarin $(200 \mu \mathrm{g} / \mathrm{ml})$, Fcblock $(10 \mu \mathrm{g} / \mathrm{ml})$, or bartonella LPS $(160 \mathrm{ng} / \mathrm{ml})$ were preincubated with BMDMs for $1 \mathrm{~h}$ at $37^{\circ} \mathrm{C}$ prior to stimulation with riclinoctaose.

\section{Statistical Analysis}

All data are expressed as means \pm SD. The statistical analysis was performed using GraphPad Prism 8 (Graph Pad Prism Software Inc., San Diego, CA, United States). All the experiments were repeated at least 3 times, and each data set shown is the representative data. Replicate measurements were taken from distinct biological samples. Data were analyzed by the two-way ANOVA followed by Bonferroni post hoc analysis, and $p$-values $<0.05$ were considered significant. 
A

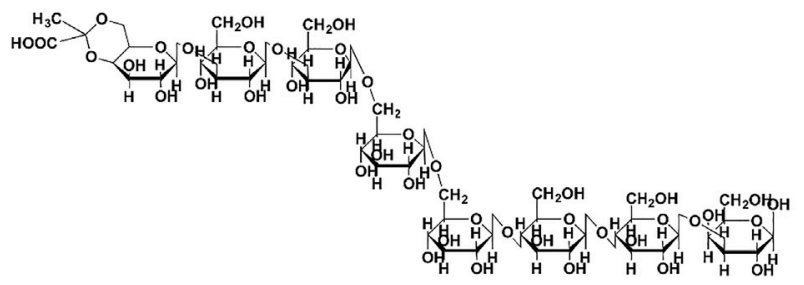

B

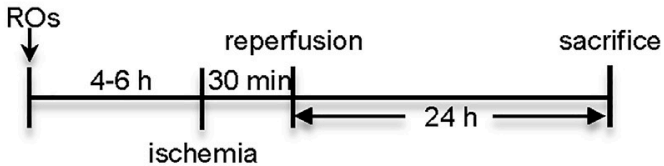

C
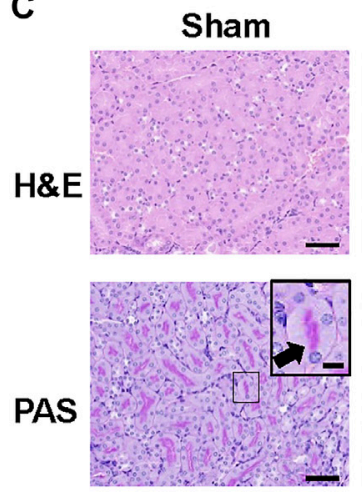

D

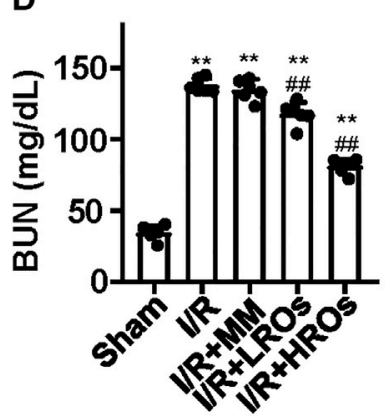

I/R
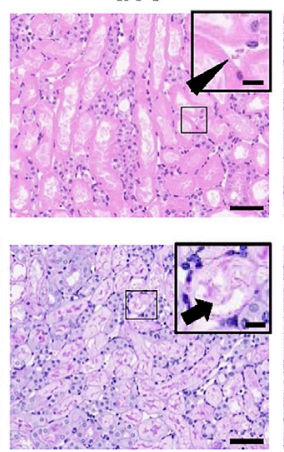

$\mathrm{E}$

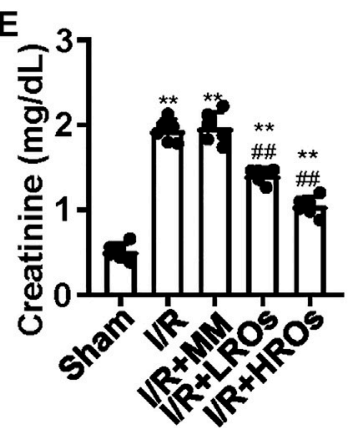

$\mathrm{I} / \mathrm{R}+\mathrm{MM}$
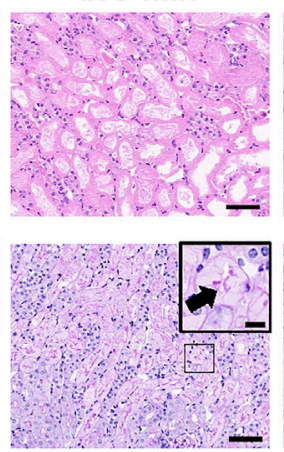

$\mathbf{F}$

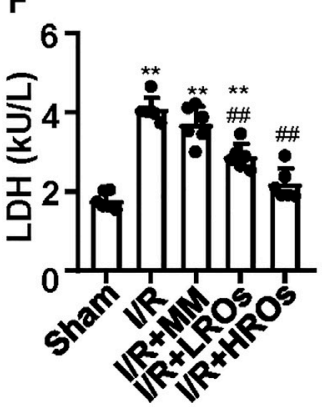

I/R+LROs

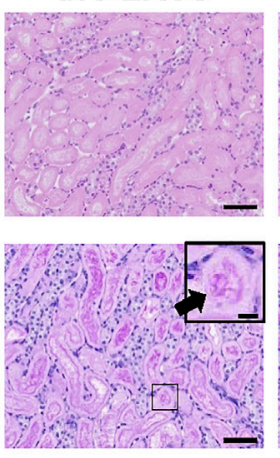

G

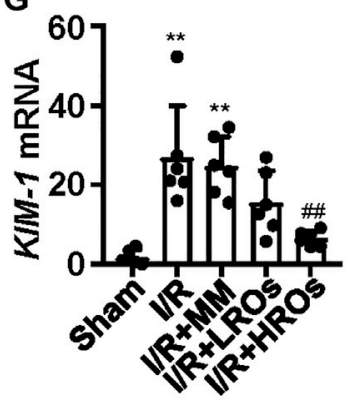

FIGURE 1 | Functional and morphological protection from renal IRI with riclinoctaose at $24 \mathrm{~h}$ after reperfusion. (A) Chemical structure of riclinoctaose. (B) Schema for in vivo experiments. C57BL/6 mice underwent sham or I/R operation. I/R mice were treated with a peritoneal injection of vehicle, monosaccharide mix (MM: galactose 5 mg/kg and glucose 35 mg/kg), or riclinoctaose (LROs: 20 mg/kg; HROs: 40 mg/kg) 4-6 h before the 30 min-ischemia and sacrificed 24 h after reperfusion. (C) Upper panel: representative kidney section stained for hematoxylin and eosin ( $\mathrm{H}$ and $\mathrm{E})$ in each mice group. Arrowhead indicates cell debris. Lower panel: representative kidney section stained with Periodic acid-Schiff (PAS) in each mice group. Arrowheads indicate brush border. (D-F) Blood urea nitrogen (BUN) levels (D), serum levels of creatinine $(\mathrm{Cre})(\mathrm{E})$, and lactate dehydrogenase $(\mathrm{LDH})(\mathrm{F})$ in each mice group. (G) Kim1 mRNA levels in kidneys of the four groups of mice. ROs: Riclinoctaose. Data are expressed as mean \pm SD. $n=6,{ }^{*} p<0.05,{ }^{* *} p<0.01$ compared with the sham group; \#p $<0.05$, \#\#p $<0.01$ compared with the l/R group. Data were analyzed by the two-way ANOVA followed by Bonferroni post hoc analysis.

\section{RESULTS}

\section{Pretreatment of Riclinoctaose Prevents Against Renal IRI}

Riclinoctaose is an octasaccharide with a stable pyruvate modification (Figure 1A). In order to examine whether riclinoctaose prevents renal IRI, the mice were pretreated with riclinoctaose $4-6 \mathrm{~h}$ before the $30 \mathrm{~min}$-ischemia and sacrificed $24 \mathrm{~h}$ after reperfusion (Figure 1B). I/R resulted in the morphological alterations in the kidney, including tubular necrosis, intratubular cellular debris, and marked loss of the proximal tubular brush border. Pretreatment of riclinoctaose (LROs: $20 \mathrm{mg} / \mathrm{kg}$; HROs: $40 \mathrm{mg} / \mathrm{kg}$ ) strikingly ameliorated IRI-induced histopathological characteristics with a dose-dependent manner (Figure 1C). Consistent with the histologic data, levels of blood urea nitrogen (BUN), creatinine, and lactate dehydrogenase were significantly increased in the kidneys of the $\mathrm{I} / \mathrm{R}$ group compared with the sham group and riclinoctaose significantly alleviated the above changes (Figures 1D-F, Supplementary Figure 2A-C). The mRNA levels of kidney injury molecule-1 (KIM-1) in the kidney were used as a metric to assess nephrotoxicity, which was increased $\sim 20 \mathrm{x}$ compared to the sham group at $24 \mathrm{~h}$ after reperfusion, and riclinoctaose groups LROs and HROs showed $\sim 34$ and $~ 70 \%$ lower than the I/R group, respectively (Figure 1G, Supplementary Figure 2D). These results indicated that pretreatment of riclinoctaose prevents against renal IRI in mice. 


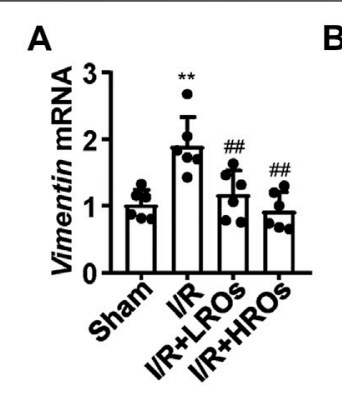

E

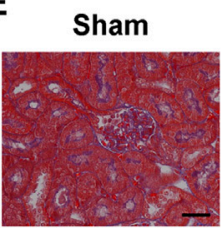

B

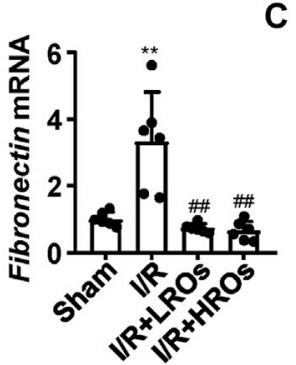

I/R
C

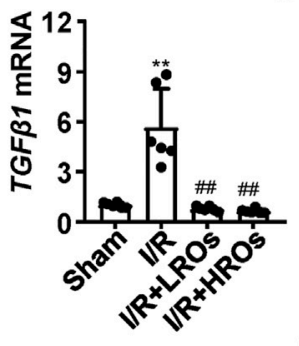

D

F

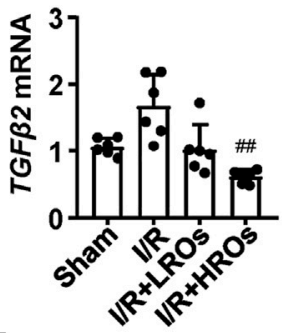

//R+HROs
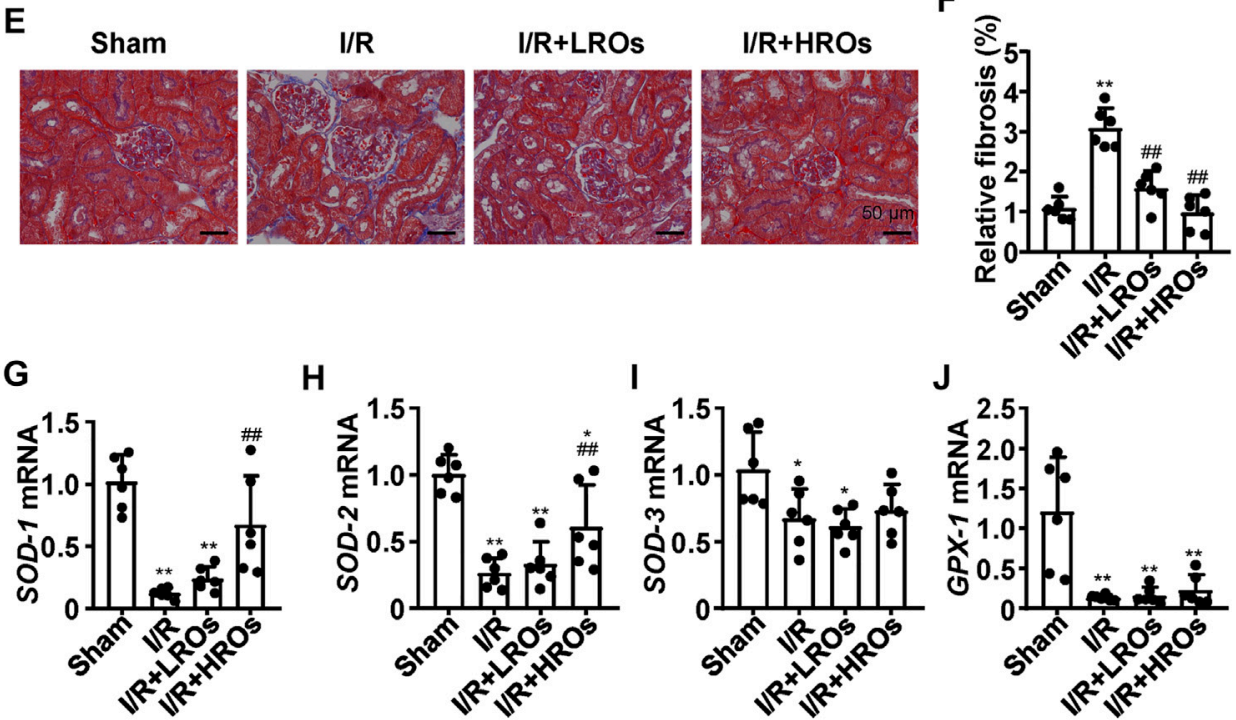

H
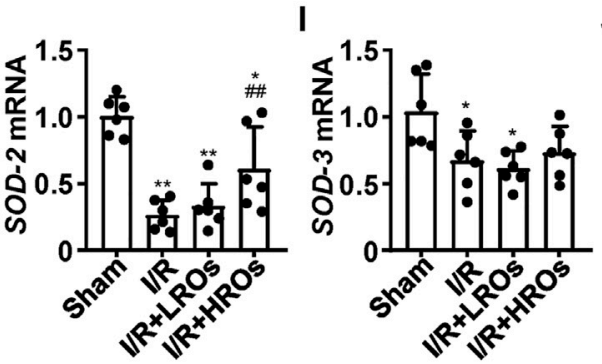

J
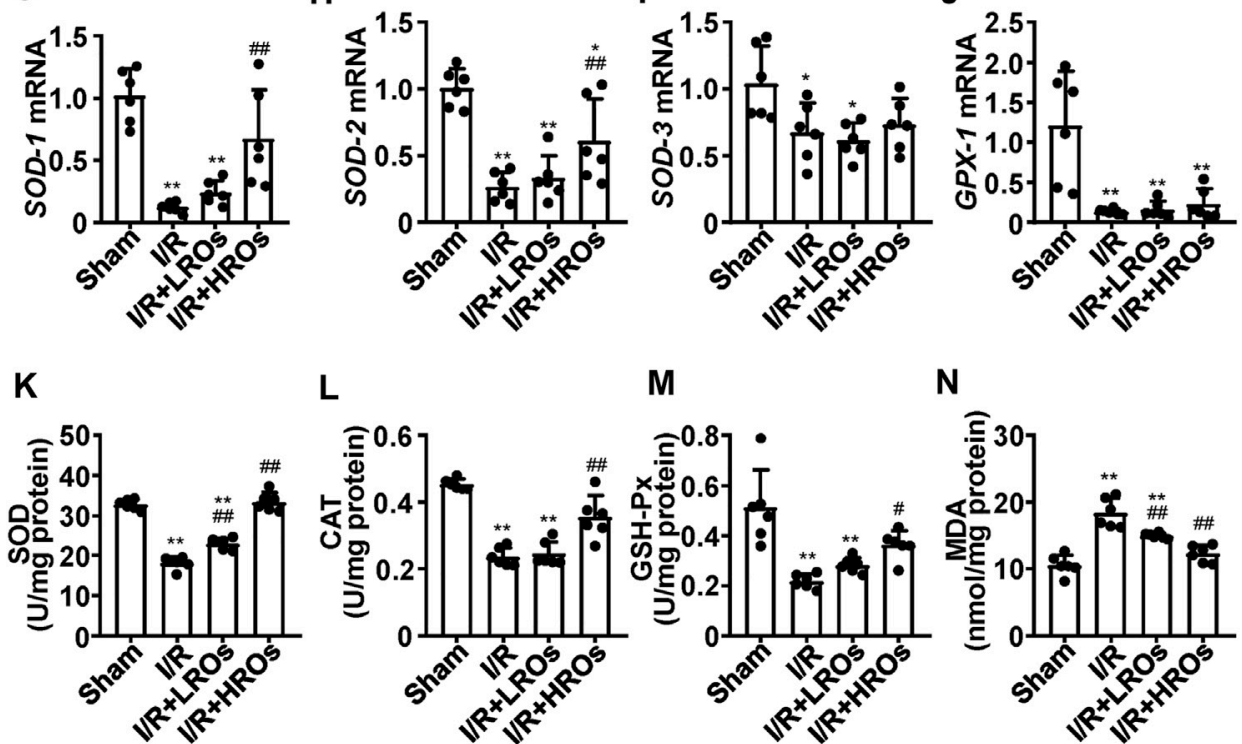

N

FIGURE 2 | Suppression of I/R-induced fibrosis and oxidative stress with riclinoctaose. (A-D) mRNA levels of fibrotic genes, Vimentin (A), Fibronectin (B), TGF- $\beta 1$ (C), and TGF- $\beta 2$ (D) in kidneys of the sham group, I/R group, I/R + LROs group, and I/R + HROs group. (E) Representative Masson's Trichrome stain of kidneys in each mice group. (F) Quantitative results of Masson staining. (G-J) mRNA levels of cellular antioxidant enzymes, SOD-1 (G), SOD-2 (H), SOD-3 (I), and GPX-1 (J) in kidneys of each mice group. (K-M) Antioxidant enzymes SOD (K), CAT (L), and GSH-Px (M) activities in the kidneys of each mice group. (N) Lipid peroxidation products MDA level in kidneys of each mice group. ROs: Riclinoctaose. Data are expressed as mean \pm SD. $n=6,{ }^{*} p<0.05,{ }^{* \star} p<0.01$ compared with the sham group; \#p $<0.05$, \#\#p $<$ 0.01 compared with the I/R group. Data were analyzed by the two-way ANOVA followed by Bonferroni post hoc analysis.

\section{Riclinoctaose Reduces I/R-Induced Kidney Fibrosis and Oxidative Stress}

Next, we examined whether riclinoctaose improves fibrosis in the kidney of I/R mice. While the mRNA levels of Vimentin and Fibronectin were markedly increased in the I/R group, riclinoctaose significantly decreased these gene expressions (Figures 2A,B). As shown in Figures 2C,D, the expression levels of TGF- $\beta 1$ and TGF- $\beta 2$ mRNA in the I/R group increased $6 \mathrm{x}$ and $1.5 \mathrm{x}$ compared with those in the sham group, pretreatment of riclinoctaose reduced these genes expression to the normal level. Consistent with the mRNA levels of various fibrogenic genes, histology showed higher levels of fibrosis within the tubulointerstitial areas in the untreated I/R mice but was markedly less in the kidneys of $I / R$ mice pretreated with riclinoctaose (Figures 2E,F). Then, we found that the mRNA levels of cellular antioxidant enzymes, including SOD-1, SOD-2, SOD-3, and GPX-1, increased after riclinoctaose (Figures 2G-J). Moreover, while SOD, CAT, and GSH-Px enzyme activities were 


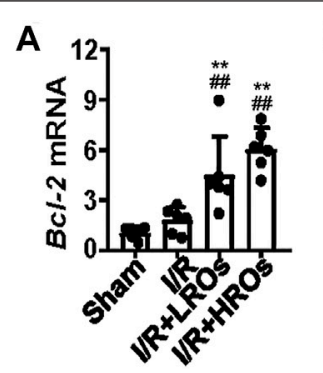

E

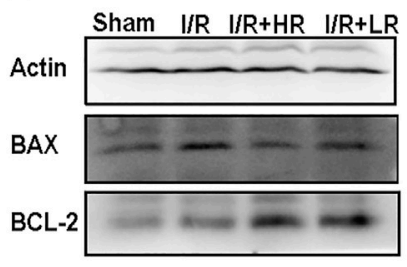

$F$

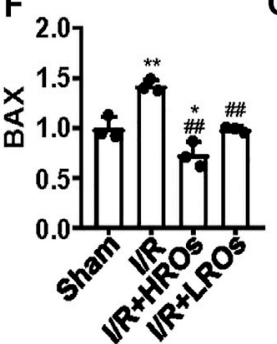

I

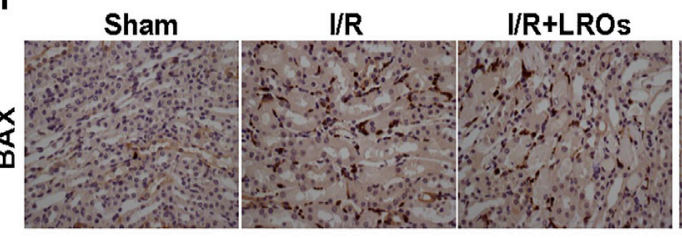

K

K Sham

I/R

I/R+LROs
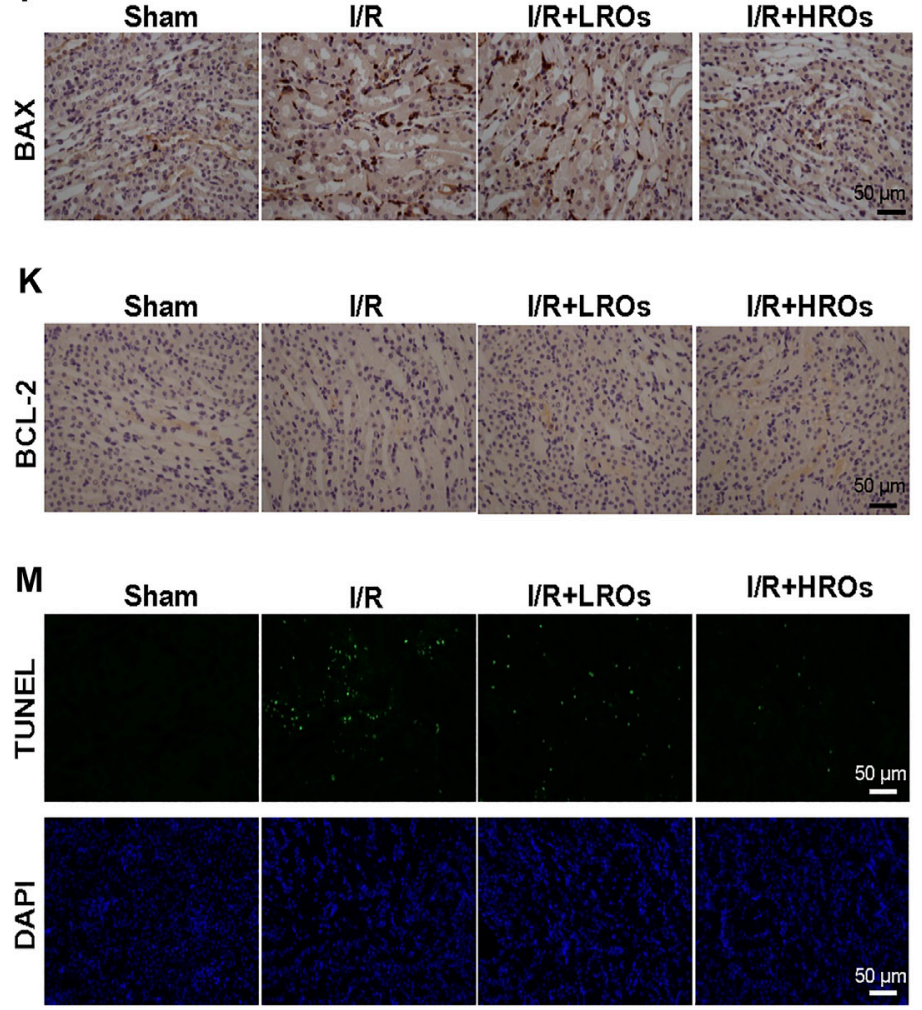

G

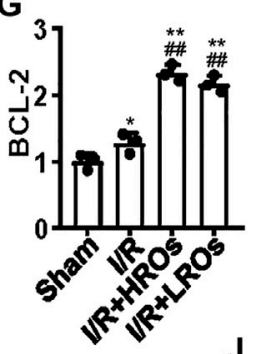

I/R+HROs

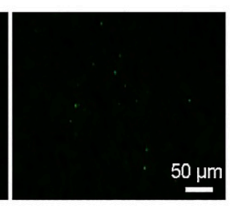

N

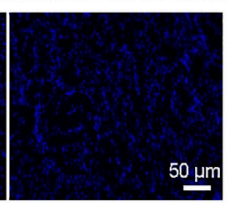

H

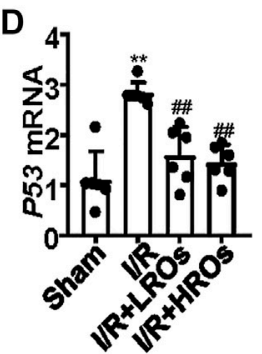

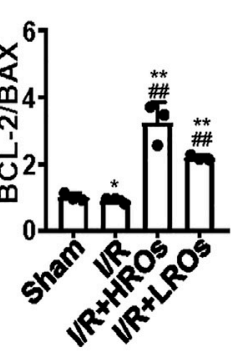
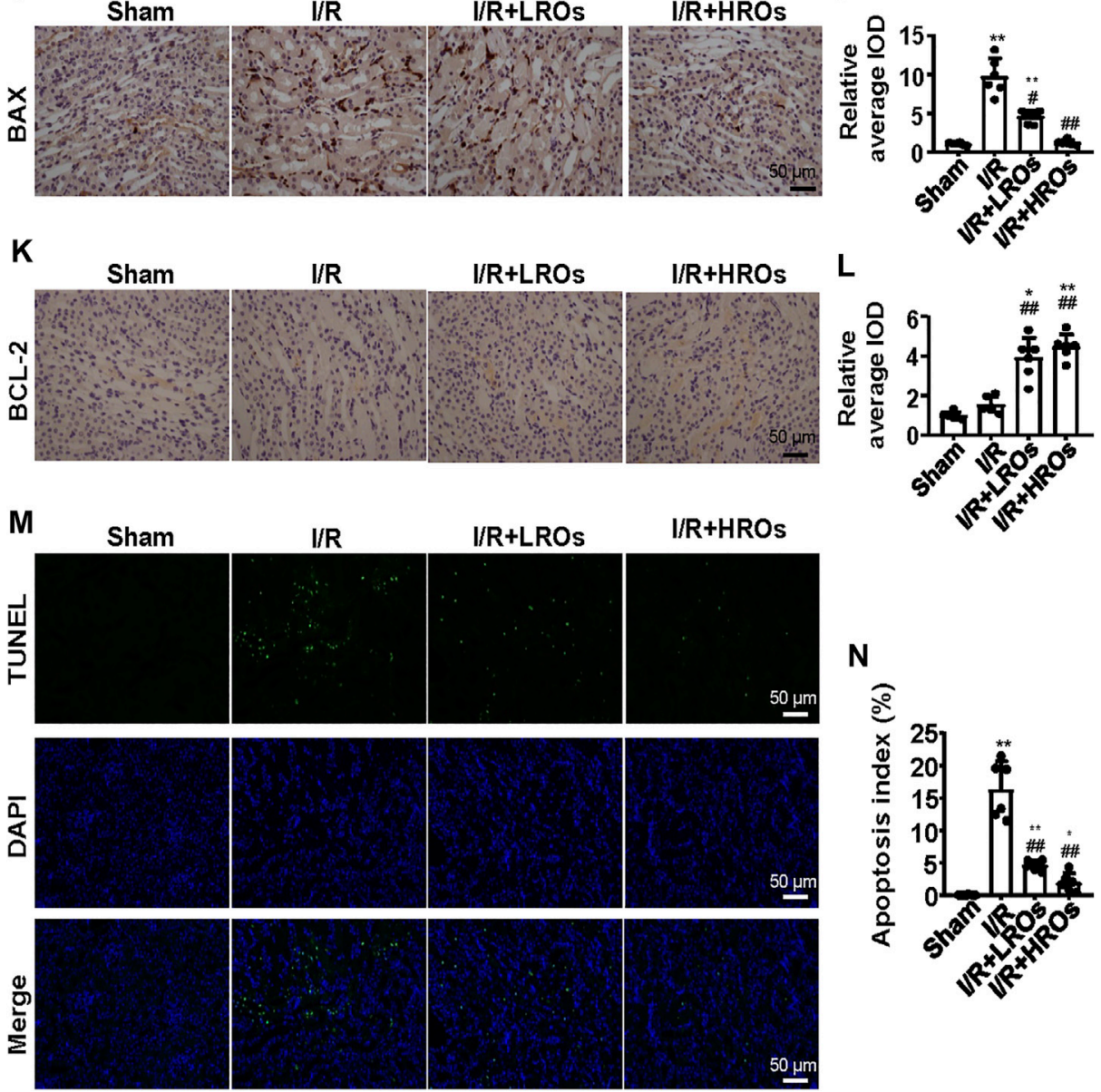

$50 \mu \mathrm{m}$

FIGURE 3 ISuppression of I/R-induced apoptosis with riclinoctaose. (A, B) Relative mRNA expression of Bax (A) and Bcl-2 (B) in the kidneys of the sham group, I/R group, I/R + LROs group, and I/R + HROs group. (C) The ratio of Bcl-2 and Bax gene expression levels. (D) mRNA level of $p 53$ in the kidneys of the four groups. (E-G) Western blot and densitometric quantitation of BAX and BCL-2 in kidneys of four groups. (H) The ratio of BCL-2 and BAX protein levels. (I, J) Representative immunohistochemistry sections (I) and quantitative results $(\mathrm{J})$ of BAX staining. $(\mathbf{K}, \mathbf{L})$ Representative immunohistochemistry sections $(K)$ and quantitative results $(\mathrm{L})$ of BCL-2 staining. (M) TUNEL-stain (green) indicates apoptosis-positive cells; DAPI stain (blue) indicates nucleated cells; the "merge" row shows cells stained with TUNEL and DAPI. (N) Quantitative results of TUNEL positive cells. ROs: Riclinoctaose. Data are expressed as mean \pm SD. $n=6$ for QRT-PCR, $n=3$ for western blotting. ${ }^{\star} p<0.05,{ }^{\star \star} p<0.01$ compared with the sham group; $\# p<0.05$, \#\# $<0.01$ compared with the I/R group. Data were analyzed by the two-way ANOVA followed by Bonferroni post hoc analysis. 

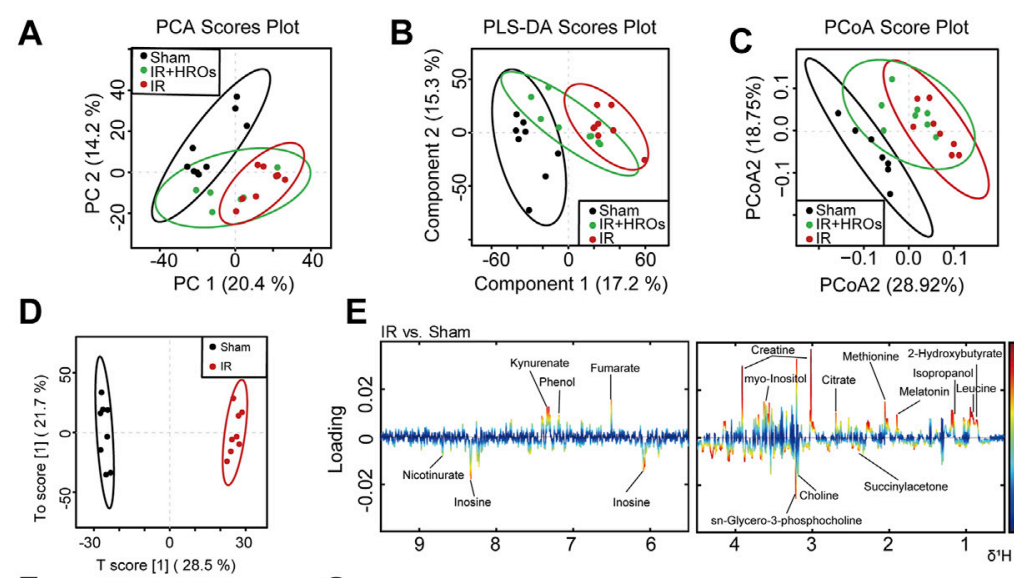

E
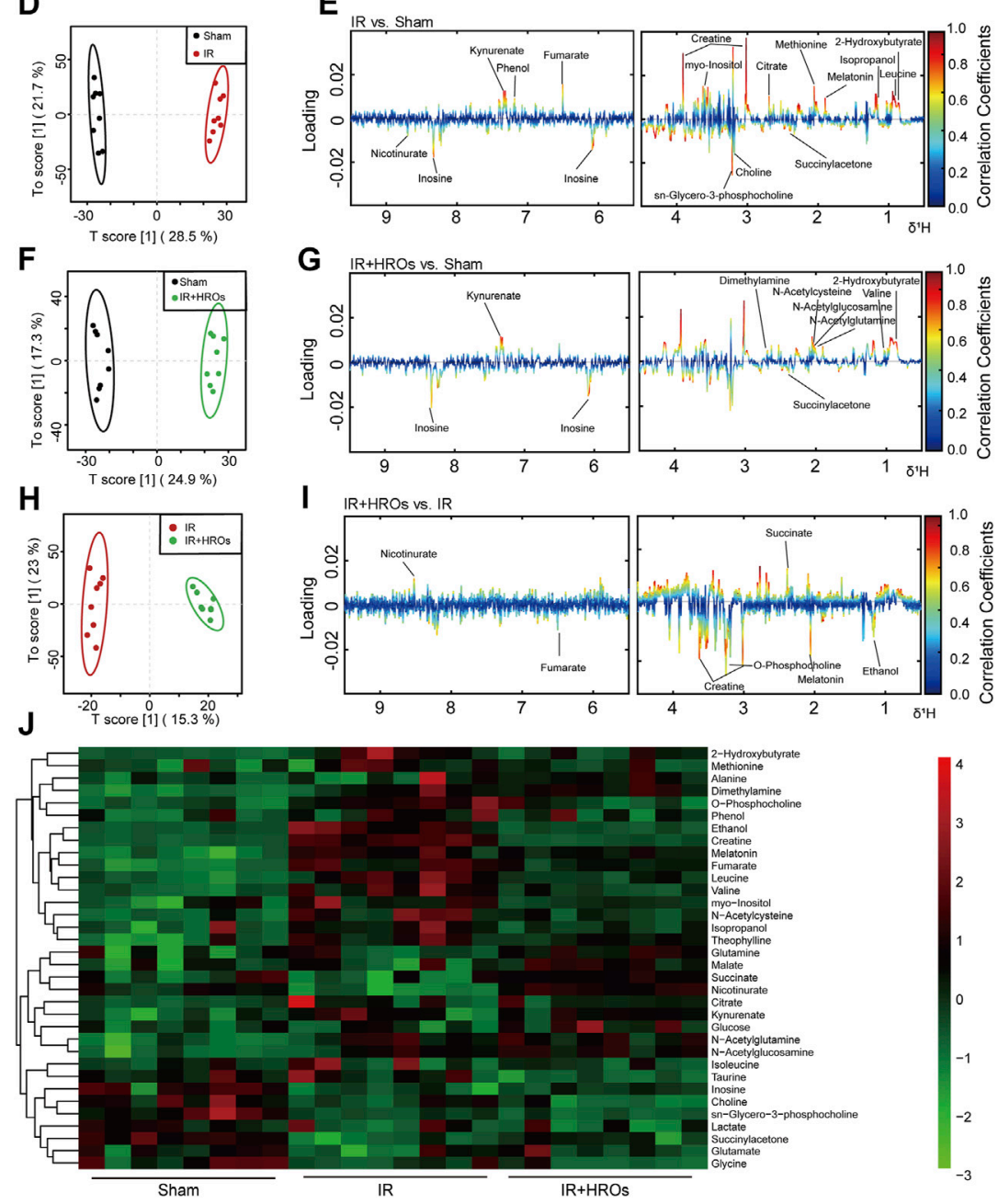

FIGURE 4 | Effects of riclinoctaose on metabolomics in the kidney. (A-C) Score plots corresponding to the PCA analysis (A), PLS-DA analysis (B), and PCoA analysis (C) of polar metabolites from the sham group, I/R group, and high-dose riclinoctaose group. (D, E) Score plots and color-coded coefficient loadings plots corresponding OPLS-DA analysis of sham group and I/R group. (F, G) Score plots and color-coded coefficient loadings plots corresponding OPLS-DA analysis of sham group and high-dose riclinoctaose (I/R + HROs) group. (H, I) Score plots and color-coded coefficient loadings plots corresponding OPLS-DA analysis of the l/R + HROs group and I/R group. (J) Heat map of 34 metabolites from the sham group, I/R group, and I/R + HROs group. ROs: Riclinoctaose. $n=8$. Symbols of solid black circles, solid red circles, and solid green circles represent the sham, I/R, and I/R + HROs groups, respectively.

substantially reduced in the kidney of I/R mice, riclinoctaose significantly recovered the enzyme activities in a dosedependent manner (Figures 2K-M). Riclinoctaose also attenuated the increases of renal MDA levels compared to those of $I / R$ mice (Figure $2 \mathrm{~N}$ ). These results showed that riclinoctaose reduces $\mathrm{I} / \mathrm{R}$-induced kidney fibrosis and oxidative stress.

\section{Riclinoctaose Suppresses I/R-Induced Apoptosis}

To further illustrate the protective effects of riclinoctaose on renal IRI, we analyzed I/R-induced apoptosis in riclinoctaose-treated mice. The mRNA level of $B c l-2$ (B cell lymphoma 2 apoptosis regulator) was slightly increased after $I / R$, and the increase was magnified to $6 x$ by riclinoctaose-pretreatment compared to the sham group (Figure 3A). 
TABLE 2 | Identified metabolites in kidneys and their fold-change values and associated $p$ values.

\begin{tabular}{|c|c|c|c|c|c|c|c|}
\hline \multirow{2}{*}{$\mathrm{NO}$} & \multirow{2}{*}{ Metabolites } & \multicolumn{2}{|c|}{ I/R vs. Sham } & \multicolumn{2}{|c|}{ I/R +HROs vs. Sham } & \multicolumn{2}{|c|}{ I/R +HROs vs. I/R } \\
\hline & & $\log _{2}(\mathrm{FC})^{\mathrm{a}}$ & $\mathrm{p}^{\mathrm{b}}$ & $\log _{2}(\mathrm{FC})^{\mathrm{a}}$ & $\mathrm{p}^{\mathrm{b}}$ & $\log _{2}(\mathrm{FC})^{\mathrm{a}}$ & $\mathrm{p}^{\mathrm{b}}$ \\
\hline 1 & 2-Hydroxybutyrate & 1.42 & $*$ & 0.81 & $*$ & -0.61 & $*$ \\
\hline 2 & Leucine & 0.98 & $*$ & 0.44 & $* *$ & -0.54 & $* *$ \\
\hline 3 & Isoleucine & 0.53 & & -0.16 & & -0.69 & \\
\hline 4 & Valine & 1.84 & $*$ & 0.71 & $*$ & -1.13 & $* *$ \\
\hline 5 & Isopropanol & 0.76 & $*$ & 0.16 & & -0.61 & $* *$ \\
\hline 6 & Ethanol & 1.93 & $*$ & 0.13 & & -1.80 & $* *$ \\
\hline 7 & Lactate & -0.08 & & -0.17 & * & -0.08 & \\
\hline 8 & Alanine & 0.09 & & 0.13 & & 0.04 & \\
\hline 9 & Melatonin & 0.84 & $*$ & 0.67 & $* *$ & -0.17 & $*$ \\
\hline 10 & N-Acetylcysteine & 0.80 & $*$ & 0.33 & $*$ & -0.47 & $*$ \\
\hline 11 & N-Acetylglutamine & 0.47 & $*$ & 0.48 & $* *$ & 0.01 & \\
\hline 12 & N-Acetylglucosamine & 0.29 & $*$ & 0.35 & $* *$ & 0.06 & \\
\hline 13 & Glutamate & -0.13 & & -0.04 & & 0.09 & \\
\hline 14 & Succinate & -0.37 & & 0.31 & $*$ & 0.69 & $* *$ \\
\hline 15 & Glutamine & 0.07 & & 0.30 & $*$ & 0.23 & $* *$ \\
\hline 16 & Citrate & 1.37 & $*$ & 1.16 & $* *$ & -0.21 & \\
\hline 17 & Methionine & 0.48 & & 0.12 & & -0.36 & \\
\hline 18 & Malate & 0.07 & & 0.31 & & 0.24 & $*$ \\
\hline 19 & Dimethylamine & 0.89 & $*$ & 1.00 & $* *$ & 0.11 & \\
\hline 20 & Succinylacetone & -1.31 & $*$ & -0.65 & $* *$ & 0.66 & $*$ \\
\hline 21 & Creatine & 1.62 & $*$ & 0.14 & & -1.48 & $* *$ \\
\hline 22 & Choline & -0.16 & $*$ & -0.30 & & -0.13 & $*$ \\
\hline 23 & O-Phosphocholine & 0.61 & $*$ & 0.20 & & -0.41 & $* *$ \\
\hline 24 & sn-Glycero-3- & -0.66 & $*$ & -0.84 & $* *$ & -0.18 & $*$ \\
\hline 25 & Taurine & 0.03 & & -0.30 & & -0.33 & $* *$ \\
\hline 26 & Theophylline & 0.73 & $*$ & 0.53 & $* *$ & -0.20 & \\
\hline 27 & Glucose & -0.03 & & 0.26 & $*$ & 0.28 & $*$ \\
\hline 28 & Glycine & -0.29 & $*$ & -0.41 & $* *$ & -0.12 & \\
\hline 29 & myo-Inositol & 0.23 & $*$ & 0.07 & & -0.17 & $* *$ \\
\hline 30 & Inosine & -0.54 & $*$ & -0.36 & $* *$ & 0.18 & \\
\hline 31 & Fumarate & 1.50 & $*$ & 1.08 & $* *$ & -0.42 & $* *$ \\
\hline 32 & Phenol & 0.53 & $*$ & 0.22 & & -0.31 & \\
\hline 33 & Kynurenate & 0.82 & $*$ & 0.91 & $* *$ & 0.09 & \\
\hline 34 & Nicotinurate & -0.80 & $*$ & 0.25 & $* *$ & 1.05 & $* *$ \\
\hline
\end{tabular}

${ }^{a}$ Color-coded according to the fold-change value. Red indicates the increased and blue represents the decreased concentrations of lipid components in compared groups. Color bar: ${ }^{-2}{ }^{0}$

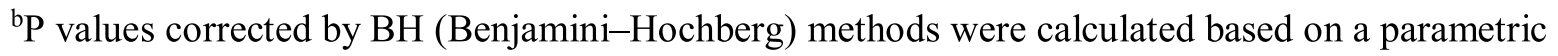
Student's t-test (dependent on the conformity to the normal distribution). ${ }^{*} \mathrm{P}<0.05,{ }^{*} * \mathrm{P}<0.01$.

The mRNA levels of Bax (pro-apoptotic proteins bcl-2 associated X protein) were increased more than $4 \mathrm{x}$ in the kidneys of $\mathrm{I} / \mathrm{R}$ mice, as compared to the sham group, and riclinoctaose-pretreatment reduced the extent of induction (Figure 3B). Correspondingly, treatment with riclinoctaose significantly upregulated the ratio of $B c l-2 / B a x$ in $I / R$ group kidneys from $\sim 0.6 \mathrm{x}$ to $7 \mathrm{x}$ compared to the sham group
(Figure 3C). The mRNA levels of $p 53$ were increased $3 \mathrm{x}$ in the kidneys of untreated I/R mice compared to the sham mice, and riclinoctaose reduced the extent of induction (Figure 3D). Consistent with gene expression, the protein levels of BAX and BCL-2 increased, and the BCL-2/BAX ratio decreased in the kidney of $\mathrm{I} / \mathrm{R}$ mice compared to that of sham mice (Figures 3E-H, left). Significantly, 

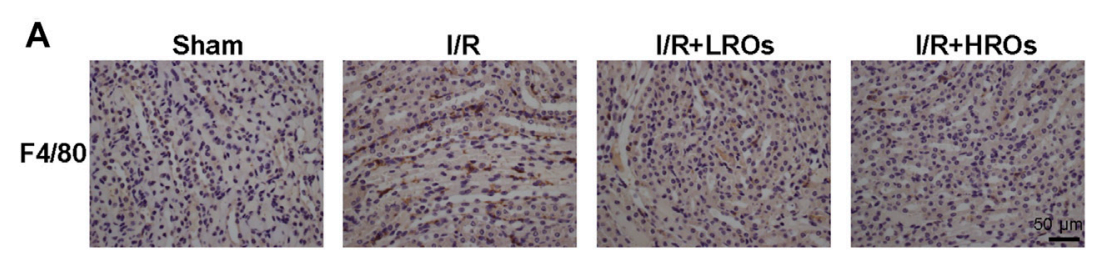

B
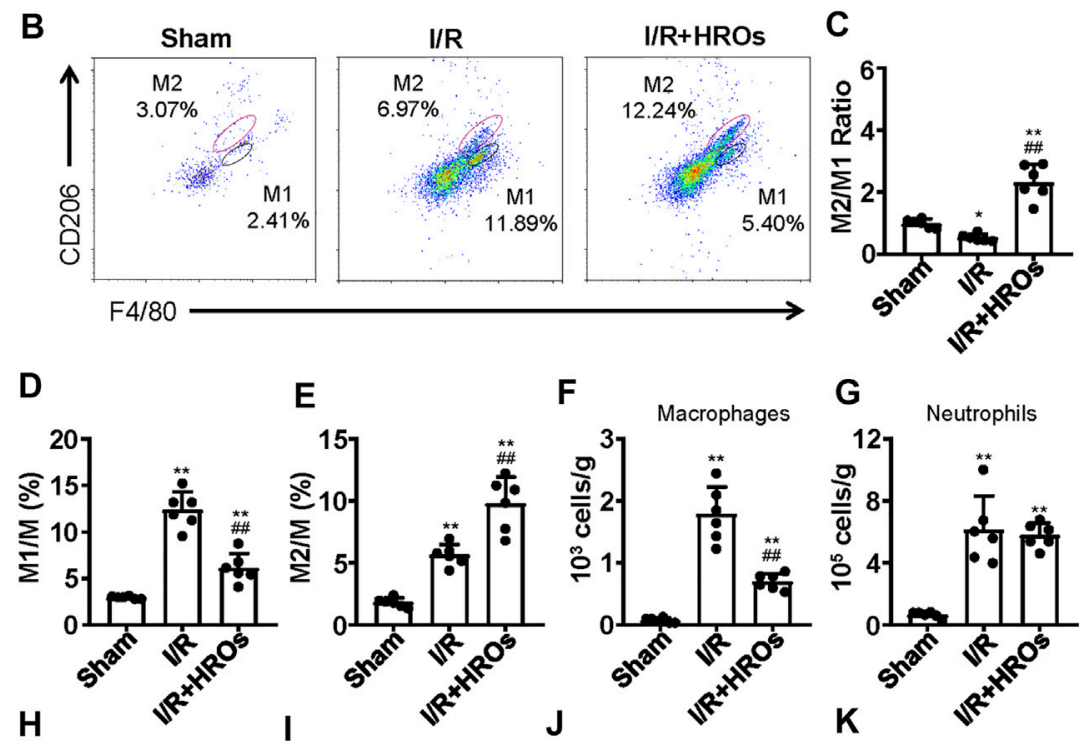

F Macrophages
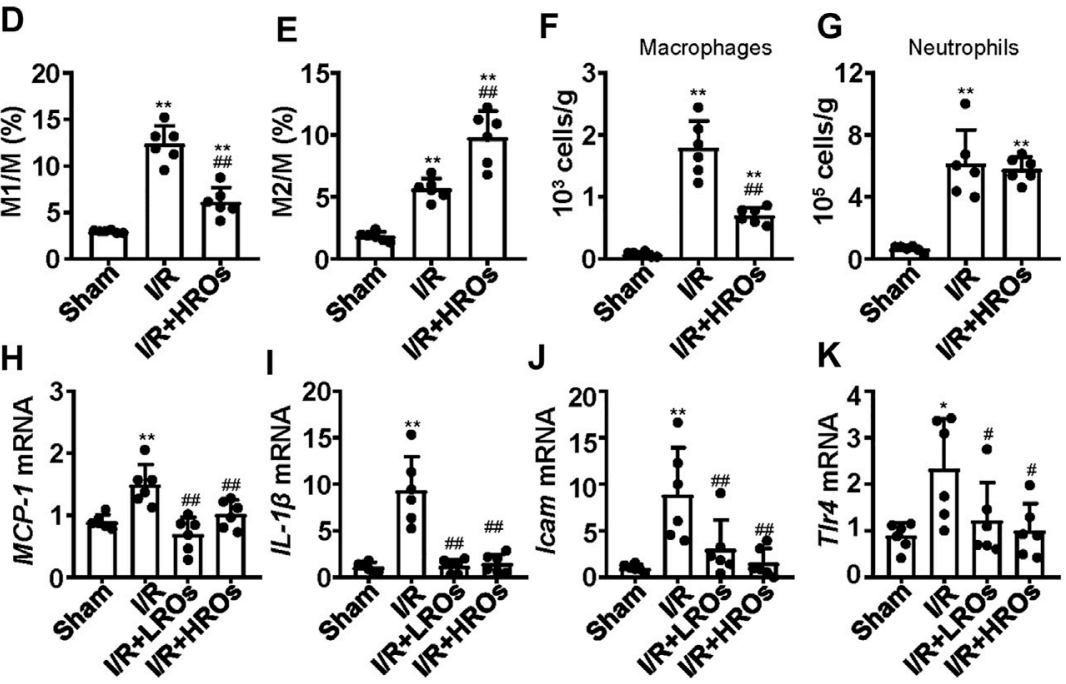

FIGURE 5 | Effects of riclinoctaose on macrophage polarization and macrophage infiltration. (A) Typical immunohistochemical staining for anti-F4/80 of the kidneys in the sham group, V/R group, VR + LROs group, and VR + HROs group. (B) Representative plot chats of flow cytometry analyzing M1 and M2 macrophages after gating CD11b + Ly-6G-cells in the kidneys of the sham group, IR group, and I/R + HROs group. M2 macrophages were defined as CD11b + Ly-6G-F4/80 + CD206-and M1 macrophages were defined as CD11b + Ly-6G-F4/80 + CD206+. (C) The ratio of M1/M2 macrophages in kidneys of the three groups. (D,E) The percentages of M1 macrophages and M2 macrophages in kidneys of the three groups. (F, G) The numbers of total macrophages and neutrophils were determined in the kidney of the three groups. (H-K) mRNA expression levels of $M C P-1(\mathrm{H}), I L-1 \beta(\mathrm{I})$, Icam $(\mathrm{J})$, and $7 \mathrm{r} 4(\mathrm{~K})$ were examined by quantitative PCR in the kidneys of the sham group, /R group, /R + LROs group, and / R + HROs group. ROs: Riclinoctaose. Data are expressed as mean $\pm S D$. $n=6,{ }^{*} p<$ $0.05,{ }^{* *} p<0.01$ compared with the sham group; $\# p<0.05, \# \# p<0.01$ compared with the IR group. Data were analyzed by the two-way ANOVA followed by Bonferroni post hoc analysis.

riclinoctaose caused a decrease of BAX, an increase of BCL-2, and an elevation of the ratio of BCL-2/BAX in a dose-dependent manner (Figures 3E-H, right). The immunohistochemical analysis confirmed the changes of these apoptosis-related proteins after riclinoctaose treatment (Figures 3I-L). Moreover, while I/R stress led to an increase in apoptosis rate, the number of TUNEL-positive cells was significantly decreased after riclinoctaose (Figures $3 \mathbf{M}, \mathbf{N}$ ). These results revealed that riclinoctaose suppresses I/R-induced apoptosis.

\section{Riclinoctaose Reverses the Shifts of Renal Metabolic Profiles of the Kidney in I/R Mice}

We then examined the effect of riclinoctaose on the metabolic profile in the $\mathrm{I} / \mathrm{R}$ kidney with ${ }^{1} \mathrm{H}$ NMR-based metabolomics analysis. In the clustered score plots, the high dose riclinoctaose-pretreated group was deviated from the untreated I/R group and closed to the sham group, indicating that riclinoctaose effectively recovered metabolic abnormality induced by IRI (Figures 4A-C). In the OPLS-DA score plot and color-coded loading plots, the I/R group showed significant shifts of the metabolites (either increase or decrease) compared to sham groups (Figures 4D,E). However, the metabolite alterations were less pronounced between the riclinoctaose-treated I/R group and the sham group (Figures 4F,G). Riclinoctaose treatment reversed the metabolite alterations caused by IRI partially (Figures 4H,I). A heatmap based on the relative abundances of the metabolites was also generated to better display the separation in metabolites between the I/R group and the sham group, as well as the similarity in metabolites among the riclinoctaose-pretreated group and sham group (Figure 4J). 
A

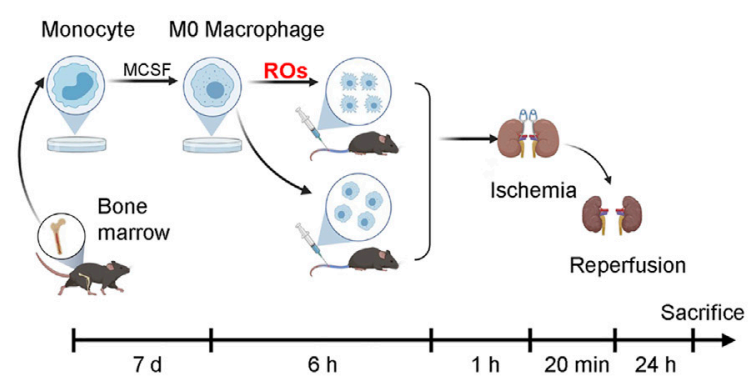

D
H\&E
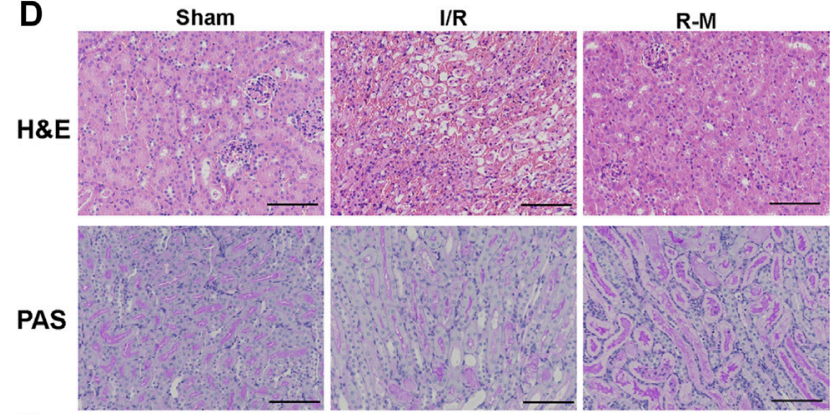

E
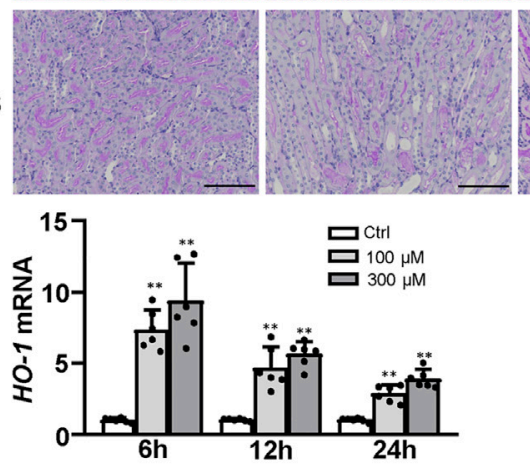

G

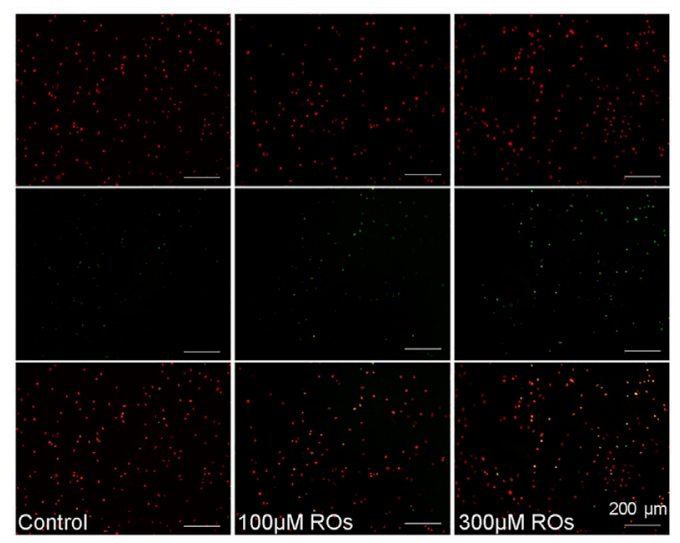

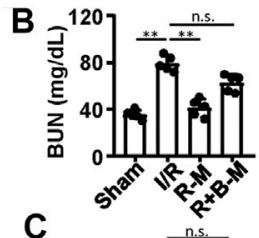

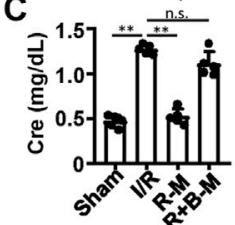

$\mathrm{R}+\mathrm{B}-\mathrm{M}$
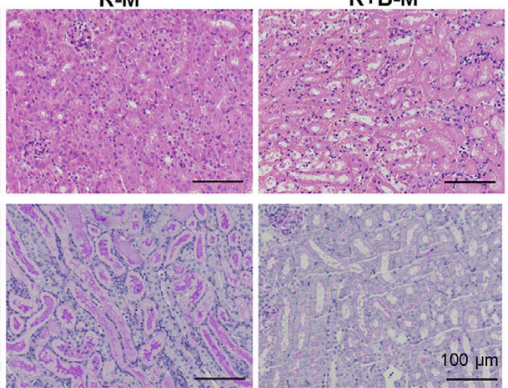

$\mathrm{F}^{12}{ }^{12} \mathrm{C}_{\mathrm{ctr}}$

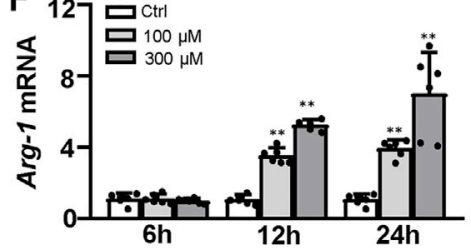

H $\square$ Ctrl $\square$ Brusatol

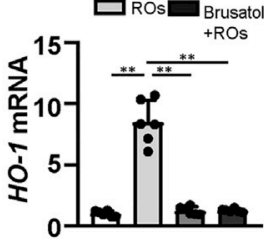

I

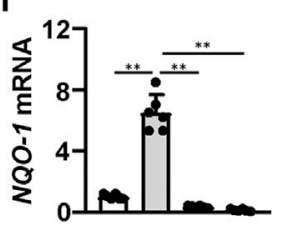

FIGURE 6 | Macrophages mediate the renoprotective effects of riclinoctaose. (A) Schematic diagram of bone marrow-derived macrophages (BMDMs) injection strategy. BMDMs were isolated from femurs and tibias, polarized for 7 days, and stimulated with vehicle or riclinoctaose for $6 \mathrm{~h}$. Then, treated BMDMs were injected intravenously $1 \mathrm{~h}$ before 20 min of bilateral ischemic, and mice were sacrificed at $24 \mathrm{~h}$ post-reperfusion. (B, C) Blood urea nitrogen (BUN) levels and serum levels of creatinine (Cre) in sham mice, mice injected with vehicle-treated BMDMs (I/R), mice injected with riclinoctaose-treated BMDMs (R-M), and mice injected with riclinoctaose and brusatol-cotreated BMDMs (R + B-M). (D) Upper panel: representative kidney section stained for hematoxylin and eosin in each mice group. Lower panel: representative kidney section stained with Periodic acid-Schiff in each mice group. (E, F) HO-1 and Arg-1 mRNA expression levels of BMDMs treated with riclinoctaose (100 and $300 \mu \mathrm{M}$ ) at different time points. (G) BMDMs (red) treated with vehicle or riclinoctaose for 6 h were incubated with apoptotic thymocytes (green) for $30 \mathrm{~min}$, and the percent of phagocytized thymocytes was determined by fluorescent microscopy. (H, I) mRNA expression levels of $H O-1$ and IL-10 in BMDMs treated with riclinoctaose or brusatol alone or co-treated with riclinoctaose and brusatol. Ctrl: Control, ROs: Riclinoctaose. Data are expressed as mean $\pm \mathrm{SD}$. $\mathrm{n}=6$, ${ }^{*} p<0.05$, ${ }^{\star \star} p<0.01$, n. s. nonsignificant. Data were analyzed by the two-way ANOVA followed by Bonferroni post hoc analysis.

The statistical analysis of major metabolites was performed and shown in Table 2. The significant elevations of the branchedchain amino acids (BCAAs), such as leucine, isoleucine and valine, in the kidneys of $\mathrm{I} / \mathrm{R}$ mice suggested the enhanced protein degradations following IRI, which could be greatly ameliorated by riclinoctaose. Besides, the significantly 
increased levels of citrate and fumarate, and the obviously decreased levels of succinate in kidneys of the I/R group showed the turbulence of the TCA cycle, and such turbulence was reversed by riclinoctaose-pretreatment. The other significantly changed levels of metabolites in the I/R group, such as 2-hydroxybutyrate, isopropanol, ethanol, $\mathrm{N}$-Acetylcysteine, succinylacetone, creatine, O-Phosphocholine, and nicotinurate were reversed after riclinoctaose pretreatment, suggesting good protection of riclinoctaose against IRI-induced metabolites disorder in mice. These results indicated that riclinoctaose reverses the shifts of renal metabolic profiles of the kidney in $\mathrm{I} / \mathrm{R}$ mice.

\section{Riclinoctaose Induces M2 Macrophage Polarization and Suppression of Myeloid-Derived Macrophage Infiltration}

In order to determine whether the above protective phenotype of riclinoctaose on renal IRI is likely mediated by the macrophages, we investigated the effects of riclinoctaose on macrophage polarization and myeloid-derived macrophage infiltration in kidney tissues. Immunohistochemical staining analysis showed that an accumulation of F4/80+ myeloid-derived macrophages occurred in the kidney of mice $24 \mathrm{~h}$ after I/R, which was blocked by pretreatment with riclinoctaose (Figure 5A). Flow cytometry analysis indicated reciprocal changes of myeloid-derived macrophage $(\mathrm{CD} 11 \mathrm{~b}+\mathrm{F} 4 / 80+)$ polarization with decreased M1 macrophages (CD11b + Ly-6G-F4/80 + CD206-) and increased M2 macrophages (CD11b + Ly-6G-F4/80 + CD206+) after riclinoctaose (Figures 5B-E). We also observed an enhanced infiltration of myeloid-derived macrophages after $\mathrm{I} / \mathrm{R}$, and riclinoctaose significantly reversed these changes (Figure 5F). Riclinoctaose did not affect neutrophil infiltration after I/R (Figure 5G). The mRNA level of pro-inflammatory cytokines related to the M1 macrophage phenotype, including $M C P-1, I L-1 \beta, I C A M$, and Tlr4, was significantly reduced after riclinoctaose (Figures $\mathbf{5 H}-\mathbf{K})$. Together, these data suggested that riclinoctaose promotes myeloid-derived macrophage polarization from the M1 to M2 phenotype.

\section{Intravenous Injection With Riclinoctaose-Treated Macrophages Improves Renal IRI}

To assess whether the effects of riclinoctaose on the myeloidderived macrophage polarization contribute to the protection of renal IRI, we isolated the bone marrow-derived macrophages (BMDMs) and stimulated them with riclinoctaose for the indicated periods. BMDMs were aliquoted into three groups: vehicle, riclinoctaose, riclinoctaose plus brusatol. These treated BMDMs were injected intravenously $1 \mathrm{~h}$ before $20 \mathrm{~min}$ of bilateral ischemic (Figure 6A). Mice injected with riclinoctaose-treated $\mathrm{BMDMs}$ showed improved renal function (BUN and Creatinine) (Figures 6B,C). The $\mathrm{H}$ and $\mathrm{E}$ and PAS staining results confirmed the protective effects of riclinoctaose. (Figure 6D). Interestingly, a selective Nrf-2 inhibition brusatol blocked the effect of riclinoctaose on preventing renal IRI
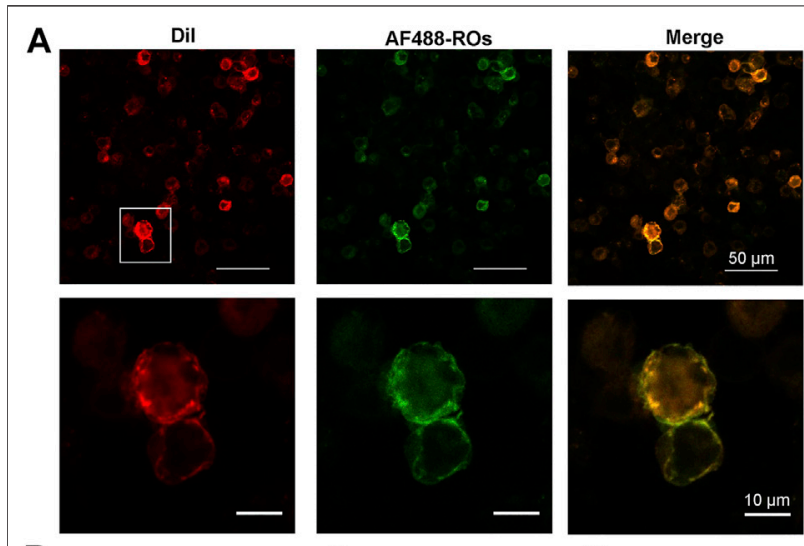

B
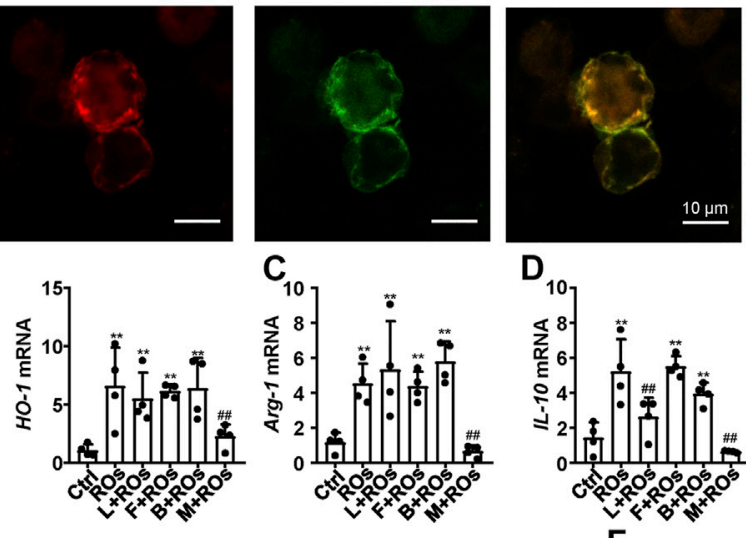

Sham

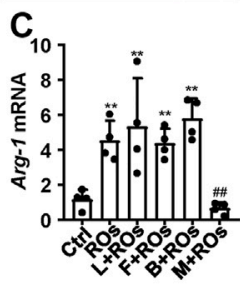

D
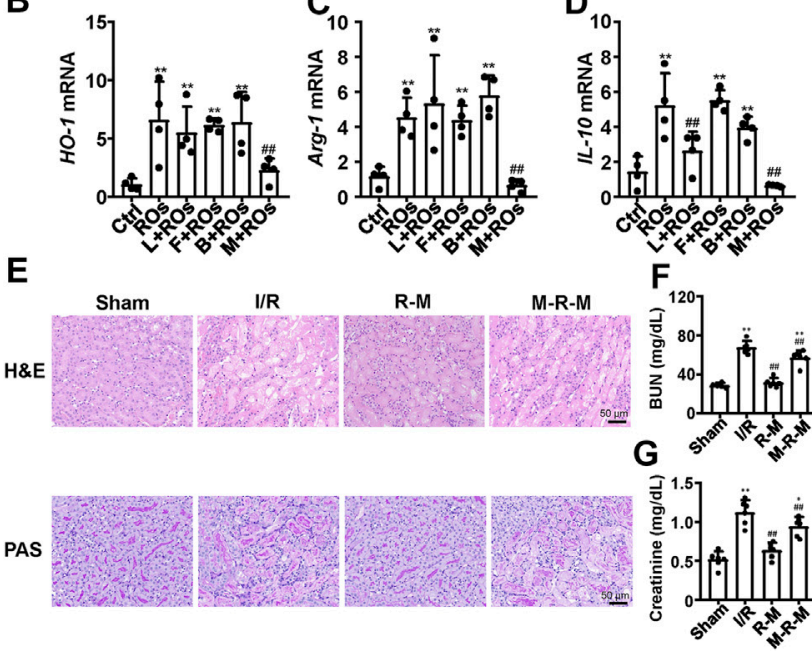

FIGURE 7 | Interfering with $\mathrm{mDC}$-SIGN blocked the riclinoctaose function (A) Colocalization of AF488-labeled riclinoctaose and cell membrane dye. Raw 267.4 cells were incubated with AF488-riclinoctaose for $6 \mathrm{~h}$, then strained for confocal microscopy with Dil (red cell membrane dye). (B-D) mRNA expression levels of HO-1, Arg-1, and /L-10 in BMDMs pretreated with vehicle, laminarin $(200 \mu \mathrm{g} / \mathrm{ml})$, Fcblock $(10 \mu \mathrm{g} / \mathrm{ml})$, bartonella LPS (160 ng/ml), or mannan $(200 \mu \mathrm{g} / \mathrm{ml})$ before riclinoctaose-treatment $(300 \mu \mathrm{M})$. (E) Upper panel: representative kidney section stained for hematoxylin and eosin ( $\mathrm{H}$ and E) in sham mice, $I / R$ mice, mice treated with riclinoctaose $(R-M)$, and mice treated with riclinoctaose and mannan (M-R-M). Lower panel: representative kidney section stained with Periodic acid-Schiff (PAS) in each mice group. (F-G) Blood urea nitrogen (BUN) levels and serum levels of creatinine in each mice group. Ctrl: Control, ROs: Riclinoctaose. Data are expressed as mean \pm SD. $n=6,{ }^{*} p<0.05,{ }^{* *} p<0.01$ compared with the sham group or control group; $\# p<0.05$, \#\#p < 0.01 compared with the I/R group or ROs group. Data were analyzed by the two-way ANOVA followed by Bonferroni post hoc analysis.

(Figures 6B-D). These results suggested that riclinoctaose improved renal IRI by altering macrophage polarization, likely through the activation of the Nrf-2 pathway. Nrf-2 is a transcription factor that increases the transcription of $\mathrm{HO}-1$, which modulates macrophage polarization towards M2 macrophage. Then, we observed that riclinoctaose caused a significant increase of the mRNA level of $H O-1$, reaching a plateau at $6 \mathrm{~h}$ in BMDMs (Figure 6E). Arginase 1 (Arg-1, a representative M2 marker) mRNA expression also increased 
significantly at $12 \mathrm{~h}$ after riclinoctaose and rose continuously until $24 \mathrm{~h}$ in BMDMs (Figure 6F). A dose-dependent enhancement of phagocytosis presented in riclinoctaose-treated BMDMs (Figure 6G). Moreover, riclinoctaose significantly elevated the expressions of $\mathrm{HO}-1$ and NQO-1, downstream factors of Nrf2 in BMDMs, and the effects of riclinoctaose on HO-1 and NQO-1 was entirely blocked by an Nrf-2 specific inhibitor brusatol (Figures 6H,I). Taken together, these results revealed that the protective effect of riclinoctaose on renal IRI is through the Nrf-2/HO-1 modulated macrophage polarization.

\section{Interfering With mDC-SIGN Blocked the Riclinoctaose Function}

Then we investigated how riclinoctaose functions on macrophages. Riclinoctaose was conjugated to the AF-488 via carbodiimide reagents EDC and NHS. Cultural macrophage cell line Raw 267.4 exhibited strong fluorescence and remained unchanged after further incubation in fresh media for $1 \mathrm{~h}$ (Supplementary Figure 3A). On the contrary, AML-12 and NIH-3T3 cells exhibited none of the fluorescence signal (Supplementary Figure 3B,C). To further visualize the localization of riclinoctaose in live cells, AF488-riclinoctaosetreated cells were incubated with a specific dye for the cell membrane. As shown in Figure 7A, the fluorescence of the dye was found to co-localize well with the green channel of AF488-riclinoctaose, suggesting that riclinoctaose bound specifically to the membrane of macrophages. Then, we focused on verifying the interaction of riclinoctaose with macrophages surface receptors. BMDMs were incubated with riclinoctaose for $6 \mathrm{~h}$ in the presence of mannans, laminarin, Fcblock, or bartonella LPS, which blocks mDC-SIGN, Dectin1, Fc $\gamma \mathrm{R}$, and TLR4, respectively. Pretreatment of mannan inhibited riclinoctaose-induced $\mathrm{HO}-1$ production by greater than 50\% and nearly fully reversed Arg-1 and IL-10 production, and laminarin, Fcblock, or bartonella LPS did not significantly alter the expression of the landmark genes regulated by riclinoctaose (Figures $7 \mathbf{B}-\mathbf{D}$ ). The intravenous injection of BMDMs with co-treatment of riclinoctaose and mannan markedly weaken the protective effect of riclinoctaose on IRI (Figures 7E-G). The above results suggest that $\mathrm{mDC}-\mathrm{SIGN}$ is potentially responsible for the recognition of the riclinoctaose by mouse macrophages.

\section{DISCUSSION}

Previous evidence has shown that some oligosaccharides exert various biological effects, including anti-inflammatory, antioxidant capacity, and antibacterial (Sutthasupha and Lungkaphin, 2020; Wang et al., 2020; Bi et al., 2021; He et al., 2021). However, these studies were limited to that the vast majority of oligosaccharides are mixture contained oligosaccharides with different degrees of polymerization. Riclinoctaose is an octasaccharide with a definite chemical structure (Wang et al., 2021). Different from other polysaccharides or oligosaccharides, riclinoctaose has great potential as a drug molecular because the production quality of riclinoctaose can be controlled precisely. In this study, we demonstrated the protective effect of riclinoctaose against severe IRI. The protective effects of riclinoctaose were evidenced by multiple criteria, including decreased tubular injury and decreased plasma BUN, creatinine, and lactate dehydrogenase, as well as inhibition of markers of inflammation, fibrosis, and apoptosis. In addition, riclinoctaose promotes M2 polarization of kidney-infiltrating macrophages. Intravenous injection with riclinoctaose-treated macrophages could essentially mimic the therapeutic effects of riclinoctaose in vivo. The inhibition of the Nrf-2/HO-1 pathway blocked the renoprotective effects of riclinoctaose. These findings provided substantial evidence that the therapeutic effect of riclinoctaose is primarily via the polarization of macrophages.

Macrophage is a heterogeneous cell population that undergoes M1 or M2 activation in response to extracellular cues (Sica and Mantovani, 2012). A biphasic effect of mononuclear phagocytes after IRI has been reported (Lee et al., 2011). Early infiltrating M1 macrophages are mainly responsible for the clearance of apoptotic cells and sublethally injured cells, which may worsen the initial level of kidney injury and further impair glomerular filtration (Lee et al., 2011; Clements et al., 2016). There is a subsequent switch to an alternatively activated M2 macrophage phenotype, which modulates the immune response to promote repair and fibrosis (Murray and Wynn, 2011; Sica and Mantovani, 2012). Riclinoctaose mainly acts during the pro-inflammatory phase of the renal $\mathrm{I} / \mathrm{R}$ model and promotes earlier myeloid-derived macrophage transformation to an anti-inflammation phenotype, which finally leads to a reduction in renal injury.

Nrf-2 is the upstream regulator of cellular responses against environmental stresses, and itself has been demonstrated to mediate inhibition of the inflammatory cytokine gene expression in M1 macrophages (Kobayashi et al., 2016). Besides, Nrf-2 induces the expression of detoxification and antioxidant enzymes, such as HO-1. There are multiple reports that increased HO-1 exhibits critical immunomodulatory functions in macrophages (Ferenbach et al., 2010; Bolisetty et al., 2017; Zhang et al., 2018). HO-1 catalyzes the degradation of pro-oxidant heme into iron, carbon monoxide, and biliverdin. The anti-inflammatory and cytoprotective effects of HO-1 have been previously observed in different models of renal disease, often hindered by the lack of an appropriate HO-1 inducer (Bolisetty et al., 2017; Zhang et al., 2018). Our results revealed that riclinoctaose is an excellent inducer of HO-1 and promotes the polarization of M2 macrophages. Riclinoctaose-treated macrophages also increased IL-10 mRNA production, a potent anti-inflammatory cytokine reported to inhibits the production of iNOS in macrophages and protects against renal ischemia-induced injury (Deng et al., 2001). The beneficial effects of IL-10 expression are mediated by HO-1 (Lee and Chau, 2002; Chen et al., 2005).

Riclinoctaose binds specifically to the membrane of macrophages but not parenchymal cells or fibroblasts, and riclinoctaose requires $\mathrm{mDC}-\mathrm{SIGN}$ to induce $\mathrm{Nrf}-2 / \mathrm{HO} 1-$ dependent M2 polarization. The interfering of riclinoctaose/ $\mathrm{mDC}-\mathrm{SIGN}$ blocked the function of riclinoctaose on M2 


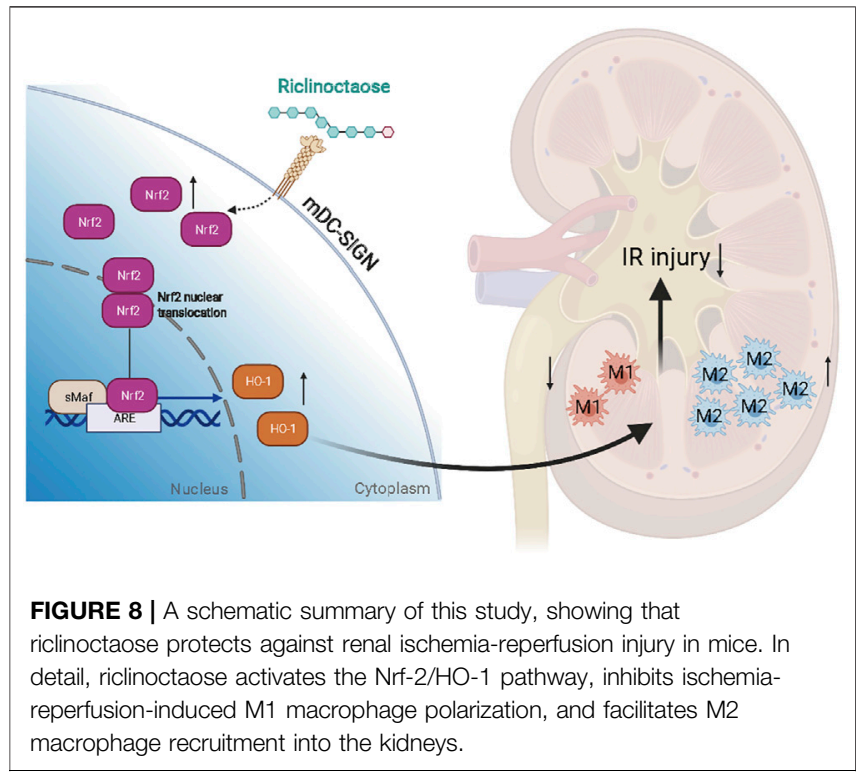

polarization, consequently impairing the renoprotective effect of riclinoctaose. hDC-SIGN was reported to be highly expressed on the population of myeloid cells (Geijtenbeek et al., 2000), and it has turned out to be a target for developing antiviral drugs since it can interact with viral glycans to facilitate virus spreading and exacerbates inflammatory reactions (Jarvis et al., 2019; Fittolani et al., 2021; Ramos-Soriano and Rojo, 2021). hDC-SIGN has been found to be involved in pattern recognition of a broad range of pathogen-derived ligands, meditation of intercellular adhesion, and self-glycoproteins receptor (van Kooyk and Geijtenbeek, 2003; Garcia-Vallejo and van Kooyk, 2013; Jarvis et al., 2019). Recently, hDC-SIGN has gained considerable attention for its participation in the infection process of several pathogens (Fittolani et al., 2021; Ramos-Soriano and Rojo, 2021). Mouse DC-SIGN is one of a family of C-type lectin genes syntenic and homologous to human DC-SIGN. Though there are significant differences in the fine specificity of the C-type lectin domains between mDC-SIGN and hDC-SIGN, mDC-SIGN shares the majority of functions of hDC-SIGN (Garcia-Vallejo and van Kooyk, 2013). There are no previous reports on the hDCSIGN/mDC-SIGN function in IRI, neither ongoing clinical or preclinical studies based on the therapeutic potential of hDCSIGN. Riclinoctaose is a promising candidate for clinical studies for protecting renal IRI.

Though we have revealed the potential riclinoctaose/mDCSIGN as the therapeutic strategy of IRI, future studies to identify a series of oligosaccharides targeting DC-SIGN will be critical. Beyond the Nrf-2/HO-1 pathway that has been thoroughly studied in this study, further exploration will be required to understand detailed mechanistic links $\mathrm{mDC}$-SIGN and IRI. These studies may help the broader therapeutic potential of mDC-SIGN as a target in IRI treatment and present comprehensive therapeutic effects. In summary, riclinoctaose exhibited excellent anti-inflammatory properties in vitro and in vivo, which may provide further insights into riclinoctaose as an attractive therapeutic agent for inflammatory-related diseases. The identified effect of riclinoctaose/mDC-SIGN could open a new therapeutic avenue for renal IRI by modulated the polarization of M2 macrophages and guide the future development of effective therapies by exploring the immunomodulatory activity of carbohydrates targeting $\mathrm{mDC}$ SIGN.

\section{CONCLUSION}

Our results demonstrated that riclinoctaose might be a potential candidate agent for the treatment of renal IRI (Figure 8). The polarization of macrophages induced by Nrf-2/HO-1 activation was demonstrated to regulate the renoprotective effect of riclinoctaose and $\mathrm{mDC}-\mathrm{SIGN}$ is potentially responsible for the recognition of the riclinoctaose by mouse macrophages.

\section{DATA AVAILABILITY STATEMENT}

The original contributions presented in the study are included in the article/Supplementary Material, further inquiries can be directed to the corresponding authors.

\section{ETHICS STATEMENT}

The animal study was reviewed and approved by the Institutional Animal Care and Use Committee at Nanjing University of Science and Technology.

\section{AUTHOR CONTRIBUTIONS}

Conceived and designed the research: YZ, RC, and JZ. Performed the experiments: YZ, ZD, WG, JL, and XX. Analyzed the data: YZ, $\mathrm{XX}$, and RC. Contributed reagents/materials/analysis tools: XX and RC. Wrote the paper: YZ and JZ. All authors edited and approved of the final article.

\section{FUNDING}

This work was supported by the National Natural Science Foundation of China (NSFC) (No. 31861163004, 31871178) and the Fundamental Research Funds for the Central Universities (No. 30920031102).

\section{SUPPLEMENTARY MATERIAL}

The Supplementary Material for this article can be found online at: https:/www.frontiersin.org/articles/10.3389/fphar.2021.745425/ full\#supplementary-material 


\section{REFERENCES}

Beckonert, O., Keun, H. C., Ebbels, T. M., Bundy, J., Holmes, E., Lindon, J. C., et al. (2007). Metabolic Profiling, Metabolomic and Metabonomic Procedures for NMR Spectroscopy of Urine, Plasma, Serum and Tissue Extracts. Nat. Protoc. 2 (11), 2692-2703. doi:10.1038/nprot.2007.376

Bi, R., Yue, L., Niazi, S., Khan, I. M., Sun, D., Wang, B., et al. (2021). Facile Synthesis and Antibacterial Activity of Geraniol Conjugated Chitosan Oligosaccharide Derivatives. Carbohydr. Polym. 251, 117099. doi:10.1016/j.carbpol.2020.117099

Bolisetty, S., Zarjou, A., and Agarwal, A. (2017). Heme Oxygenase 1 as a Therapeutic Target in Acute Kidney Injury. Am. J. Kidney Dis. 69 (4), 531-545. doi:10.1053/j.ajkd.2016.10.037

Boor, P., and Floege, J. (2015). Renal Allograft Fibrosis: Biology and Therapeutic Targets. Am. J. Transpl. 15 (4), 863-886. doi:10.1111/ajt.13180

Chen, S., Kapturczak, M. H., Wasserfall, C., Glushakova, O. Y., CampbellThompson, M., Deshane, J. S., et al. (2005). Interleukin 10 Attenuates Neointimal Proliferation and Inflammation in Aortic Allografts by a Heme Oxygenase-dependent Pathway. Proc. Natl. Acad. Sci. U S A. 102 (20), 7251-7256. doi:10.1073/pnas.0502407102

Choi, J. M., Kim, H., Cho, E., Choi, Y., Lee, I. S., and Jung, S. (2012). Solubilization of Haloperidol by Acyclic Succinoglycan Oligosaccharides. Carbohydr. Polym. 89 (2), 564-570. doi:10.1016/j.carbpol.2012.03.048

Clements, M., Gershenovich, M., Chaber, C., Campos-Rivera, J., Du, P., Zhang, M., et al. (2016). Differential Ly6C Expression after Renal Ischemia-Reperfusion Identifies Unique Macrophage Populations. J. Am. Soc. Nephrol. 27 (1), 159-170. doi:10.1681/asn.2014111138

Deng, J., Kohda, Y., Chiao, H., Wang, Y., Hu, X., Hewitt, S. M., et al. (2001). Interleukin-10 Inhibits Ischemic and Cisplatin-Induced Acute Renal Injury. Kidney Int. 60 (6), 2118-2128. doi:10.1046/j.1523-1755.2001.00043.x

Devarajan, P. (2006). Update on Mechanisms of Ischemic Acute Kidney Injury. J. Am. Soc. Nephrol. 17 (6), 1503-1520. doi:10.1681/asn.2006010017

Erkasap, S., Erkasap, N., Koken, T., Kahraman, A., Uzuner, K., Yazihan, N., et al. (2004). Effect of Leptin on Renal Ischemia-Reperfusion Damage in Rats. J. Physiol. Biochem. 60 (2), 79-84. doi:10.1007/bf03168443

Ferenbach, D. A., Ramdas, V., Spencer, N., Marson, L., Anegon, I., Hughes, J., et al. (2010). Macrophages Expressing Heme Oxygenase-1 Improve Renal Function in Ischemia/reperfusion Injury. Mol. Ther. 18 (9), 1706-1713. doi:10.1038/ $\mathrm{mt} .2010 .100$

Fittolani, G., Shanina, E., Guberman, M., Seeberger, P. H., Rademacher, C., and Delbianco, M. (2021). Automated Glycan Assembly of 19 F-Labeled Glycan Probes Enables High-Throughput NMR Studies of Protein-Glycan Interactions. Angew. Chem. Int. Ed. Engl. 60 (24), 13302-13309. doi:10.1002/anie.202102690

Garcia-Vallejo, J. J., and van Kooyk, Y. (2013). The Physiological Role of DC-SIGN: a Tale of Mice and Men. Trends Immunol. 34 (10), 482-486. doi:10.1016/ j.it.2013.03.001

Geijtenbeek, T. B., Torensma, R., van Vliet, S. J., van Duijnhoven, G. C., Adema, G. J., van Kooyk, Y., et al. (2000). Identification of DC-SIGN, a Novel Dendritic Cell-specific ICAM-3 Receptor that Supports Primary Immune Responses. Cell 100 (5), 575-585. doi:10.1016/s0092-8674(00)80693-5

Gonsalez, S. R., Cortês, A. L., Silva, R. C. D., Lowe, J., Prieto, M. C., and Silva Lara, L. D. (2019). Acute Kidney Injury Overview: From Basic Findings to New Prevention and Therapy Strategies. Pharmacol. Ther. 200, 1-12. doi:10.1016/ j.pharmthera.2019.04.001

Haddad, G., Kölling, M., Wegmann, U. A., Dettling, A., Seeger, H., Schmitt, R., et al. (2021). Renal AAV2-Mediated Overexpression of Long Non-Coding RNA H19 Attenuates Ischemic Acute Kidney Injury through Sponging of microRNA-30a-5p. J. Am. Soc. Nephrol. 32 (2), 323-341. doi:10.1681/ asn. 2020060775

He, L., Yan, B., Yao, C., Chen, X., Li, L., Wu, Y., et al. (2021). Oligosaccharides from Polygonatum Cyrtonema Hua: Structural Characterization and Treatment of LPS-Induced Peritonitis in Mice. Carbohydr. Polym. 255, 117392. doi:10.1016/ j.carbpol.2020.117392

Huen, S. C., and Cantley, L. G. (2017). Macrophages in Renal Injury and Repair. Annu. Rev. Physiol. 79, 449-469. doi:10.1146/annurev-physiol-022516-034219

Ihtiyar, E., Yaşar, N. F., Erkasap, N., Köken, T., Tosun, M., Oner, S., et al. (2011). Effects of Doxycycline on Renal Ischemia Reperfusion Injury Induced by
Abdominal Compartment Syndrome. J. Surg. Res. 167 (1), 113-120. doi:10.1016/j.jss.2009.09.048

Jarak, I., Carrola, J., Barros, A. S., Gil, A. M., Pereira, M. L., Corvo, M. L., et al. (2017). From the Cover: Metabolism Modulation in Different Organs by Silver Nanoparticles: An NMR Metabolomics Study of a Mouse Model. Toxicol. Sci. 159 (2), 422-435. doi:10.1093/toxsci/kfx142

Jarvis, C. M., Zwick, D. B., Grim, J. C., Alam, M. M., Prost, L. R., Gardiner, J. C., et al. (2019). Antigen Structure Affects Cellular Routing through DC-SIGN. Proc. Natl. Acad. Sci. U S A. 116 (30), 14862-14867. doi:10.1073/ pnas. 1820165116

Kobayashi, E. H., Suzuki, T., Funayama, R., Nagashima, T., Hayashi, M., Sekine, H., et al. (2016). Nrf2 Suppresses Macrophage Inflammatory Response by Blocking Proinflammatory Cytokine Transcription. Nat. Commun. 7, 11624. doi:10.1038/ncomms11624

Korkmaz, A., and Kolankaya, D. (2009). The Protective Effects of Ascorbic Acid against Renal Ischemia-Reperfusion Injury in Male Rats. Ren. Fail. 31 (1), 36-43. doi:10.1080/08860220802546271

Kucuk, A., Kabadere, S., Tosun, M., Koken, T., Kinaci, M. K., Isikli, B., et al. (2009). Protective Effects of Doxycycline in Ischemia/reperfusion Injury on Kidney. J. Physiol. Biochem. 65 (2), 183-191. doi:10.1007/bf03179069

Lee, T. S., and Chau, L. Y. (2002). Heme Oxygenase-1 Mediates the Antiinflammatory Effect of Interleukin-10 in Mice. Nat. Med. 8 (3), 240-246. doi: $10.1038 / \mathrm{nm} 0302-240$

Lee, S., Huen, S., Nishio, H., Nishio, S., Lee, H. K., Choi, B. S., et al. (2011). Distinct Macrophage Phenotypes Contribute to Kidney Injury and Repair. J. Am. Soc. Nephrol. 22 (2), 317-326. doi:10.1681/asn.2009060615

Li, F., Bahnson, E. M., Wilder, J., Siletzky, R., Hagaman, J., Nickekeit, V., et al. (2020). Oral High Dose Vitamin B12 Decreases Renal Superoxide and postischemia/reperfusion Injury in Mice. Redox Biol. 32, 101504. doi:10.1016/ j.redox.2020.101504

Livingston, M. J., Wang, J., Zhou, J., Wu, G., Ganley, I. G., Hill, J. A., et al. (2019). Clearance of Damaged Mitochondria via Mitophagy Is Important to the Protective Effect of Ischemic Preconditioning in Kidneys. Autophagy 15 (12), 2142-2162. doi:10.1080/15548627.2019.1615822

Mora-Ortiz, M., Nuñez Ramos, P., Oregioni, A., and Claus, S. P. (2019a). NMR Metabolomics Identifies over 60 Biomarkers Associated with Type II Diabetes Impairment in Db/db Mice. Metabolomics 15 (6), 89. doi:10.1007/s11306-0191548-8

Mora-Ortiz, M., Trichard, M., Oregioni, A., and Claus, S. P. (2019b). Thanatometabolomics: Introducing NMR-Based Metabolomics to Identify Metabolic Biomarkers of the Time of Death. Metabolomics 15 (3), 37. doi:10.1007/s11306-019-1498-1

Murray, P. J., and Wynn, T. A. (2011). Protective and Pathogenic Functions of Macrophage Subsets. Nat. Rev. Immunol. 11 (11), 723-737. doi:10.1038/ nri3073

Ramos-Soriano, J., and Rojo, J. (2021). Glycodendritic Structures as DC-SIGN Binders to Inhibit Viral Infections. Chem. Commun. (Camb) 57 (42), 5111-5126. doi:10.1039/d1cc01281a

Ricardo, S. D., van Goor, H., and Eddy, A. A. (2008). Macrophage Diversity in Renal Injury and Repair. J. Clin. Invest. 118 (11), 3522-3530. doi:10.1172/ jci36150

Roach, D. R., Briscoe, H., Saunders, B., France, M. P., Riminton, S., and Britton, W. J. (2001). Secreted Lymphotoxin-Alpha Is Essential for the Control of an Intracellular Bacterial Infection. J. Exp. Med. 193 (2), 239-246. doi:10.1084/ jem.193.2.239

Sharfuddin, A. A., and Molitoris, B. A. (2011). Pathophysiology of Ischemic Acute Kidney Injury. Nat. Rev. Nephrol. 7 (4), 189-200. doi:10.1038/ nrneph.2011.16

Sica, A., and Mantovani, A. (2012). Macrophage Plasticity and Polarization: In Vivo Veritas. J. Clin. Invest. 122 (3), 787-795. doi:10.1172/jci59643

Sutthasupha, P., and Lungkaphin, A. (2020). The Potential Roles of Chitosan Oligosaccharide in Prevention of Kidney Injury in Obese and Diabetic Conditions. Food Funct. 11 (9), 7371-7388. doi:10.1039/d0fo00302f

Tang, T.-T., Wang, B., Li, Z.-L., Wen, Y., Feng, S.-T., Wu, M., et al. (2021). Kim-1 Targeted Extracellular Vesicles: A New Therapeutic Platform for RNAi to Treat AKI. Jasn, ASN.2020111561. doi:10.1681/asn.2020111561

van Kooyk, Y., and Geijtenbeek, T. B. (2003). DC-SIGN: Escape Mechanism for Pathogens. Nat. Rev. Immunol. 3 (9), 697-709. doi:10.1038/nri1182 
Vinuesa, E., Hotter, G., Jung, M., Herrero-Fresneda, I., Torras, J., and Sola, A. (2008). Macrophage Involvement in the Kidney Repair Phase after Ischaemia/ reperfusion Injury. J. Pathol. 214 (1), 104-113. doi:10.1002/path.2259

Wang, W. D., Chen, C., and Fu, X. (2020). Glycation Mechanism of LactoferrinChitosan Oligosaccharide Conjugates with Improved Antioxidant Activity Revealed by High-Resolution Mass Spectroscopy. Food Funct. 11 (12), 10886-10895. doi:10.1039/d0fo02724c

Wang, L., Cheng, R., Sun, X., Zhao, Y., Ge, W., Yang, Y., et al. (2021). Preparation and Gut Microbiota Modulatory Property of the Oligosaccharide Riclinoctaose. J. Agric. Food Chem. 69 (12), 3667-3676. doi:10.1021/acs.jafc.0c07783

Yan, J. J., Ryu, J. H., Piao, H., Hwang, J. H., Han, D., Lee, S. K., et al. (2020). Granulocyte Colony-Stimulating Factor Attenuates Renal IschemiaReperfusion Injury by Inducing Myeloid-Derived Suppressor Cells. J. Am. Soc. Nephrol. 31 (4), 731-746. doi:10.1681/asn.2019060601

Yang, Y., Sun, Q., Xu, X., Yang, X., Gao, Y., Sun, X., et al. (2019). Oral Administration of Succinoglycan Riclin Improves Diet-Induced Hypercholesterolemia in Mice. J. Agric. Food Chem. 67 (48), 13307-13317. doi:10.1021/acs.jafc.9b06034

Yang, Y., Sun, X., Zhao, Y., Ge, W., Ding, Z., Liu, J., et al. (2021). Anti-tumor Activity and Immunogenicity of a Succinoglycan Riclin. Carbohydr. Polym. 255, 117370. doi:10.1016/j.carbpol.2020.117370

Zhang, M., Nakamura, K., Kageyama, S., Lawal, A. O., Gong, K. W., Bhetraratana, M., et al. (2018). Myeloid HO-1 Modulates Macrophage Polarization and Protects against Ischemia-Reperfusion Injury. JCI Insight 3 (19). doi:10.1172/jci.insight.120596
Zhuang, S., Xia, S., Huang, P., Wu, J., Qu, J., Chen, R., et al. (2021). Targeting P2RX1 Alleviates Renal Ischemia/reperfusion Injury by Preserving Mitochondrial Dynamics. Pharmacol. Res. 170, 105712. doi:10.1016/ j.phrs.2021.105712

Zuk, A., and Bonventre, J. V. (2016). Acute Kidney Injury. Annu. Rev. Med. 67, 293-307. doi:10.1146/annurev-med-050214-013407

Conflict of Interest: The authors declare that the research was conducted in the absence of any commercial or financial relationships that could be construed as a potential conflict of interest.

Publisher's Note: All claims expressed in this article are solely those of the authors and do not necessarily represent those of their affiliated organizations, or those of the publisher, the editors and the reviewers. Any product that may be evaluated in this article, or claim that may be made by its manufacturer, is not guaranteed or endorsed by the publisher.

Copyright (C) 2021 Zhao, Ding, Ge, Liu, Xu, Cheng and Zhang. This is an open-access article distributed under the terms of the Creative Commons Attribution License (CC $B Y)$. The use, distribution or reproduction in other forums is permitted, provided the original author(s) and the copyright owner(s) are credited and that the original publication in this journal is cited, in accordance with accepted academic practice. No use, distribution or reproduction is permitted which does not comply with these terms. 